\title{
Desempenho de concretos avançados para a construção civil, formulados a partir do método de dosagem computacional
}

\section{(Performance of advanced concretes for building site designed by computing mix proportion technique)}

\author{
A. L. de Castro ${ }^{I}$, J. B. L. Liborio ${ }^{2}$, V. C.Pandolfelli ${ }^{1}$ \\ Departamento de Engenharia de Materiais, Universidade Federal de S. Carlos \\ Rod. Washington Luiz, km 235, C.P. 676, S. Carlos, SP 13565-905 \\ ${ }^{2}$ Escola de Engenharia de S. Carlos, Universidade de S. Paulo, Av. Trabalhador Sancarlense 400, S. Carlos, SP \\ 13566-590 \\ alelorencastro@yahoo.com.br,vicpando@power.ufscar.br
}

\begin{abstract}
Resumo
A busca por materiais com desempenho mecânico e durabilidade cada vez superiores tem sido o alvo dos pesquisadores da tecnologia dos concretos. Para tanto, concretos obtidos a partir da engenharia de microestrutura são necessários. Com base nos conceitos de empacotamento e dispersão de partículas é possível obter materiais com matrizes densas e trabalhabilidade adequada. Assim, as propriedades de concretos dosados com base nesses conceitos são apresentadas e comparadas àquelas de concretos de alto desempenho, adotados em pesquisas da construção civil. As propriedades no estado fresco foram avaliadas medindo-se o índice de fluidez e determinando-se o comportamento reológico do material. No estado endurecido, a resistência mecânica foi avaliada pelos ensaios de compressão uniaxial, tração por compressão diametral e flexão em 3 pontos, enquanto o módulo de elasticidade foi avaliado pelos métodos estático e dinâmico. Os concretos desenvolvidos se apresentaram trabalháveis por um período de tempo superior que o concreto de referência, sem a necessidade da incorporação de aditivos retardadores. Em termos de resistência mecânica, foi possível observar uma maior reprodutibilidade dos resultados obtidos para os concretos formulados por dosagem computacional. Além disso, os resultados possibilitaram estabelecer boas correlações entre as resistências medidas para esses concretos, bem como entre os módulos de elasticidade medidos por ambos os métodos de ensaio.

Palavras-chave: engenharia de microestrutura, dispersão e empacotamento de partículas, propriedades reológicas, resistência mecânica, concretos especiais.
\end{abstract}

\begin{abstract}
The search for materials with better mechanical performance and durability has been the aim of the concrete's technology researchers. In order to attain this target, concretes developed with engineering microstructure are necessary. Based on the concepts of particle packing and dispersion, it is possible to obtain materials with dense matrix and appropriate workability. Thus, in the present paper, the properties of concretes based on these concepts are presented and compared to those high performance ones used in building site researches. The fresh properties were evaluated measuring the fluidity index and the rheological behavior of the material. In the hardened condition, the mechanical strength were evaluated by the compressive, splitting tensile and 3 point bending tests, whereas the Young's modulus were measured by the static and dynamic methods. The new concretes showed to be more workable for a longer period of time than the reference one, without the need of retarding admixtures addition. In terms of mechanical strength, it was possible to verify higher reproducibility for the concretes designed with the computing mix proportion technique. Besides that, it was also possible to establish good correlations between the strength measured for these concretes, as well for the Young's modulus measured by both test methods.
\end{abstract}

Keywords: microstructure engineering, particle dispersion and packing, rheological properties, mechanical resistance, special concretes.

\section{INTRODUÇÃO}

Nos últimos anos, muitas pesquisas têm sido desenvolvidas na área dos concretos em busca de materiais com desempenhos superiores com relação ao comportamento mecânico e à durabilidade. Por serem compósitos constituídos de partículas com granulometria fina e uma baixa relação água/aglomerante, estes concretos apresentam matrizes densas obtidas a partir da otimização do empacotamento dos materiais granulares, enquanto a trabalhabilidade adequada é alcançada por meio da dispersão das partículas promovida pela incorporação de aditivos químicos à mistura. Com isso, a alta densidade e a correta dispersão resultam em materiais com alta resistência mecânica e durabilidade. 
A produção de concretos com trabalhabilidade adequada (quando no estado fresco) e alta resistência mecânica e durabilidade (quando no estado endurecido) é possível devido à associação de aditivos superplastificantes e adições minerais. Os superplastificantes permitem a obtenção de misturas com baixa relação água/aglomerante (menor que 0,30 ), enquanto as adições minerais, com grãos de tamanhos menores que as partículas de cimento, facilitam a produção associando seu efeito físico (efeito filler) ao efeito químico (reação pozolânica) [1].

\section{Dispersão e empacotamento de partículas}

As partículas de cimento apresentam uma grande tendência à aglomeração quando entram em contato com um líquido polar como a água, devido a vários tipos de interação: forças de atração interpartículas (forças de van der Waals), forças eletrostáticas entre posições de sítios com cargas opostas e forte interação ou ligação envolvendo as moléculas de água ou hidratos. Assumir tal estrutura aglomerada implica na retenção de certa quantidade da água de mistura e, com isso, a geração de uma rede aberta de canais entre as partículas. Essa rede de vazios pode aprisionar parte da água que, por essa razão, fica indisponível para hidratar a superfície das partículas de cimento e para fluidificar a mistura [2].

Os aglomerados formados, permanentes ou não, além de influenciar a reologia das suspensões, podem interferir no empacotamento e, conseqüentemente, na microestrutura do material. Com isso, são gerados produtos com maior quantidade e/ou tamanho de defeitos e com microestruturas heterogêneas. Assim, os aglomerados devem ser eliminados, buscando sempre suspensões dispersas que, além de apresentarem menor viscosidade, permitem a utilização de maiores concentrações de sólidos no processo. Nestas suspensões, as partículas encontramse individualizadas, sendo pouco influenciadas pela ação da gravidade, permitindo que permaneçam homogêneas e estáveis por um maior período de tempo [3].

Para se obter suspensões dispersas, as forças de repulsão entre as partículas devem superar as forças de atração. Assim, o uso de dispersantes torna-se necessário para evitar a sedimentação de partículas e conseqüente segregação de fases, possibilitando a preparação de suspensões homogêneas com alta concentração de sólidos. Esses aditivos são eficientes na desaglomeração das estruturas de partículas de cimento e em sua dispersão, evitando uma ligação prematura, minimizando a quantidade de água necessária para a adequada trabalhabilidade da suspensão e resultando em misturas trabalháveis pelo intervalo de tempo necessário à sua aplicação.

A fluidez inicial de soluções fortemente suspensas, tais como a pasta de cimento e o concreto, também depende de considerações físicas, isto é, da distribuição granulométrica, do índice de forma e da textura superficial das partículas [4]. Sendo assim, o projeto da distribuição de tamanho de partículas é de fundamental importância, pois promove o empacotamento e, juntamente com o fluido, define as características reológicas do material durante o processo de mistura e quando no estado fresco.

Nos últimos anos, o interesse pelo empacotamento das partículas tem aumentado nas diferentes áreas da engenharia. Esse interesse pode ser explicado pelo fato de que uma grande parte dos materiais naturais ou industriais com os quais lidamos diariamente são (ou contém) partículas de diferentes formas e tamanhos. Assim, o comportamento de tais materiais depende parcialmente das propriedades das partes que o compõem e parcialmente das interações entre elas [5].

Atualmente, com a utilização de superplastificantes, os concretos de alto desempenho apresentam uma maior densidade devido a redução na quantidade de água de mistura. Além disso, componentes finos e ultrafinos, com formato esférico - adições - têm sido adicionados às misturas tanto para facilitar o auto-adensamento quanto para garantir uma melhor compactação e preenchimento dos vazios existentes entre os grãos, aumentando ainda mais a densidade desses materiais [6]. Assim, o conceito de uma alta densidade de empacotamento foi recentemente redescoberto como um parâmetro chave para a obtenção de materiais cimentícios de ultra-alto desempenho.

\section{Propriedades do concreto no estado fresco}

Do ponto de vista reológico, o concreto pode ser entendido como uma concentração de partículas sólidas em suspensão (agregados) em um líquido viscoso (pasta de cimento); porém, a pasta de cimento não se configura como um líquido homogêneo, sendo composta por partículas (grãos de cimento) e um líquido (água). Em uma escala macroscópica, o concreto fresco flui como um líquido [7].

Termos como trabalhabilidade, consistência, capacidade de escoamento, mobilidade e capacidade de bombeamento têm sido usados para descrever o comportamento do concreto no estado fresco, porém eles refletem principalmente pontos de vista pessoais do que precisão científica [8]. Assim, sendo o concreto um líquido, nada mais adequado do que aplicar os conceitos da reologia ao estudo do seu comportamento quando no estado fresco.

Nos últimos anos, a reologia do concreto fresco tem sido estudada com determinações que variam entre métodos de ensaio simples e práticos, como o ensaio de abatimento de tronco de cone, até equipamentos mais sofisticados que determinam as curvas de cisalhamento do material, como os reômetros. Porém, ainda não é muito comum o uso dessa ciência para se estudar as propriedades do concreto fresco. A dificuldade da aplicação de medidas reológicas em concreto está relacionada com as grandes partículas de agregado graúdo que compõe a mistura, as quais impossibilitam o uso de reômetros tradicionais, tais como o viscosímetro capilar ou o viscosímetro cilíndrico. Porém, equipamentos com dimensões suficientemente grandes têm sido construídos, possibilitando a construção das curvas de cisalhamento desses materiais. 
Todos os métodos de ensaio normalizados, bem como qualquer outro método empírico, tentam avaliar as propriedades do concreto fresco em termos de uma quantidade única, de maneira que todos eles abrangem a consideração implícita de que o concreto se comporta da maneira mais simples possível, como um fluido newtoniano. Porém, a observação mais casual do comportamento desse material mostra que essa suposição não pode ser verídica já que o concreto exige a imposição de uma tensão ou força mínima para que ele inicie seu escoamento [9], indicando que o seu comportamento não pode ser caracterizado por uma constante única.

$\mathrm{Na}$ literatura, devido a uma vasta evidência experimental das propriedades reológicas do concreto no estado fresco, concluiu-se que o material se comporta como um fluindo plástico ou binghamiano $[7,9,10]$ para o intervalo das taxas de cisalhamento envolvidas no seu processo prático, ou seja, a tensão necessária ao escoamento do material - tensão de cisalhamento $\tau$ - é igual à soma da tensão de escoamento $\tau_{o}$ e de outro termo proporcional à taxa de cisalhamento $\dot{\gamma}$, denominado viscosidade plástica $\mu$ (equação A).

$$
\tau=\tau_{0}=\mu \dot{\gamma}
$$

A determinação de ambos os parâmetros reológicos - tensão de escoamento e viscosidade plástica - permite a diferenciação imediata de concretos que poderiam ser erroneamente considerados idênticos pelos métodos de ensaio padrões existentes. Além disso, os vários fatores que compõem uma mistura de concreto e que interferem na sua trabalhabilidade influenciam os parâmetros reológicos de maneiras diferentes. Sendo assim, o estudo da natureza das mudanças que ocorrem na mistura pode indicar o fator responsável pelas mesmas.

Para garantir um comportamento reológico estável por um determinado período de tempo, a caracterização adequada da evolução da trabalhabilidade é importante, o que pode ser facilmente monitorado com o auxílio de um reômetro. Nestes testes reométricos a amostra de concreto pode ser mantida pelo tempo necessário para que sucessivos ensaios de cisalhamento sejam executados, possibilitando acompanhar a evolução das constantes reológicas. Assim, a evolução da trabalhabilidade de um concreto pode ser descrita pela evolução dos parâmetros reológicos e determinada pelos seus efeitos combinados para uma aplicação em particular. Geralmente, o processo de perda da trabalhabilidade é refletido por um aumento da tensão de escoamento, enquanto que, na maioria dos casos, a viscosidade plástica é praticamente constante durante o período em que o ensaio é realizado (normalmente por menos de $90 \mathrm{~min}$ ) [10].

\section{Propriedades do concreto no estado endurecido}

A escolha de um material de engenharia, para uma aplicação específica, deve levar em conta a sua capacidade de resistir à aplicação de uma tensão. Dependendo de como agem sobre o material, as tensões poderão ser distinguidas umas das outras, como, por exemplo, compressão, tração, flexão, cisalhamento e torção. As relações tensãodeformação dos materiais são geralmente expressas em termos de resistência, módulo de elasticidade, ductilidade e tenacidade [11].

Geralmente a resistência é considerada como a propriedade mais importante do concreto, embora, na prática, características como durabilidade e permeabilidade sejam de fato mais importantes. Além disso, a resistência dá uma idéia geral da qualidade do concreto, uma vez que está diretamente relacionada com a estrutura da pasta de cimento hidratada. A resistência é, quase invariavelmente, um elemento essencial do projeto estrutural, sendo especificada para fins de aceitação [12]. A resistência do concreto é uma propriedade inerente do material, enquanto que como medida na prática, ela também é uma função do sistema de tensões atuantes. Para um dado conjunto de materiais, a resistência de uma mistura trabalhável, adequadamente aplicada e sob iguais condições de mistura, cura e ensaio, é influenciada pela relação entre o cimento e a água de mistura, relação entre o cimento e o agregado, granulometria, textura superficial, forma, resistência e rigidez das partículas de agregado e tamanho máximo do agregado. Assim, a resistência do concreto pode ser considerada como o resultado da resistência da pasta de cimento, da aderência entre a matriz e o agregado graúdo e a resistência das partículas de agregado, isto é, da capacidade de resistir às tensões aplicadas [12].

Além disso,existe uma relação fundamental inversa entre a porosidade e a resistência nos sólidos. Consequientemente, em materiais multifásicos como o concreto, a porosidade de cada componente ou fase de sua estrutura pode se tornar um fator limitante da resistência. Embora o fator água/cimento seja o mais importante na determinação da porosidade do concreto e, conseqüentemente, da sua resistência, fatores como adensamento, condições de cura (grau de hidratação do cimento), dimensões e mineralogia do agregado, aditivos, geometria e condições de umidade do corpo de prova, tipo de tensão e velocidade de carregamento também podem ter um efeito importante sobre a resistência [11].

A resistência real (técnica) da pasta de cimento hidratada ou de materiais frágeis similares (como o concreto) é muito menor do que a resistência teórica estimada com base na coesão molecular e calculada a partir da energia de superfície de um sólido suposto perfeitamente homogêneo e sem falhas. Essa discrepância pode ser explicada pela presença de defeitos conforme a teoria de Griffith, os quais variam de tamanho, sendo os maiores aqueles mais sujeitos ao início de propagação da trinca. Assim, a resistência de um corpo de prova é um problema de probabilidade estatística: a resistência não pode ser representada por um único valor médio, devendo indicar também a variabilidade dos resultados, bem como a forma e o tamanho dos corpos de prova [12].

No projeto de estruturas de concreto, considerase o concreto como o material mais adequado para resistir à carga de compressão; por isso, sua resistência à 
compressão é geralmente especificada. Sendo a resistência do concreto função do processo de hidratação do cimento, o qual é relativamente lento, as especificações e os ensaios de resistência desse material são tradicionalmente baseados em corpos de prova curados em condições específicas de temperatura e umidade por um período de 28 dias. Normalmente, as resistências à tração e à flexão do concreto são, aproximadamente, da ordem de $10 \%$ e $15 \%$, respectivamente, de sua resistência à compressão e a razão da grande diferença entre as resistências é atribuída à estrutura heterogênea e complexa desse material e ao distinto estado de tensão [11].

\section{MATERIAIS E MÉTODOS}

\section{Materiais}

O cimento utilizado nas composições do concreto de referência e dos novos concretos foi o cimento Portland de alta resistência inicial (CPV ARI Plus). As propriedades físicas desse cimento são: massa específica $3,16 \mathrm{~g} / \mathrm{cm}^{3}$ e área superficial (B.E.T.) $1,70 \mathrm{~m}^{2} / \mathrm{g}$. Sua composição química e sua composição potencial (determinada pelas equações de Bogue) são apresentadas na Tabela I. O teor de água ideal para uma pasta com consistência normal padronizada é dado para uma relação água/cimento igual a 0,30. A distribuição granulométrica discreta desse cimento é dada na Fig. 1.

Para a produção do concreto de referência, a brita e a

Tabela I - Composições química e potencial do CPV ARI Plus.

[Table I - Chemical and potential compositions of CPV ARI Plus.]

\begin{tabular}{cc}
\hline Óxidos & $\begin{array}{c}\text { Resultado } \\
(\%)\end{array}$ \\
\hline $\mathrm{SiO}_{2}$ & 21,16 \\
$\mathrm{Al}_{2} \mathrm{O}_{3}$ & 4,71 \\
$\mathrm{Fe}_{2} \mathrm{O}_{3}$ & 1,89 \\
$\mathrm{TiO}_{2}$ & 0,15 \\
$\mathrm{CaO}$ & 68,08 \\
$\mathrm{MgO}$ & 0,48 \\
$\mathrm{Na}_{2} \mathrm{O}$ & 0,29 \\
$\mathrm{~K}_{2} \mathrm{O}$ & 0,56 \\
$\mathrm{P}_{2} \mathrm{O}_{5}$ & 0,28 \\
$\mathrm{Perda}$ ao fogo & 2,39 \\
\hline $\mathrm{Composição} \mathrm{potencial}(\%)^{\mathrm{C}_{3} \mathrm{~S}}$ & 58,95 \\
$\mathrm{C}_{2} \mathrm{~S}$ & 10,15 \\
$\mathrm{C}_{3} \mathrm{~A}$ & 7,36 \\
$\mathrm{C}_{4} \mathrm{AF}$ & 9,46 \\
\hline
\end{tabular}

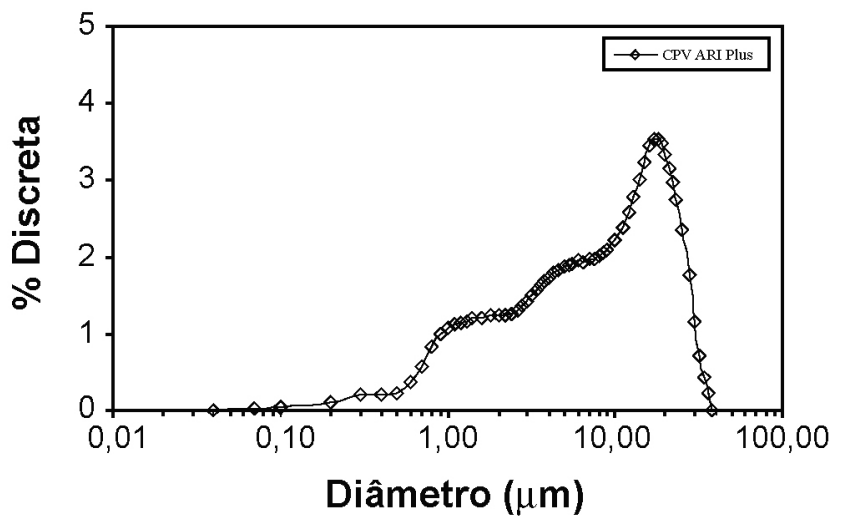

Figura 1: Distribuição granulométrica do CPV ARI Plus.

[Figure 1: Particle size distribution of CPV ARI Plus.]

areia fina foram adotados como os agregados componentes da mistura. A brita é de origem basáltica, graduada como brita 0 segundo as especificações da norma brasileira para agregado [13]. A areia utilizada é uma areia quartzosa de cava retirada de uma jazida próxima a S. Carlos, SP, e a classificação como uma areia fina também foi feita de acordo com a NBR 7211/2005. O módulo de finura e a dimensão máxima desses agregados foram determinados a partir do ensaio de composição granulométrica [14] e os valores obtidos foram, respectivamente, 5,29 e $9,5 \mathrm{~mm}$ para a brita e 2,34 e 4,8 $\mathrm{mm}$ para a areia.

Os agregados AG 10-20, AG 05-08, AG 40-50 e AG 80100 foram utilizados na composição dos novos concretos. Todos eles são areias de origem quartzosa, constituídos por grãos arredondados. A granulometria desses agregados é controlada por meio de técnicas estatísticas de tamanho efetivo e coeficiente de uniformidade, enquanto as características físicas e químicas são mantidas estáveis e em conformidade com as especificações do mercado. São areias disponíveis comercialmente pela Mineração Jundu, destinadas a produção de filtros, vidros e cerâmicas.

Adistribuição granulométrica dos agregados utilizados é apresentada na Fig. 2. A massa unitária e a massa específica desses agregados são resumidas na Tabela II.

Os pós de quartzo SM 200, SM 400 e SM 500 foram utilizados apenas na composição dos novos concretos. Esses

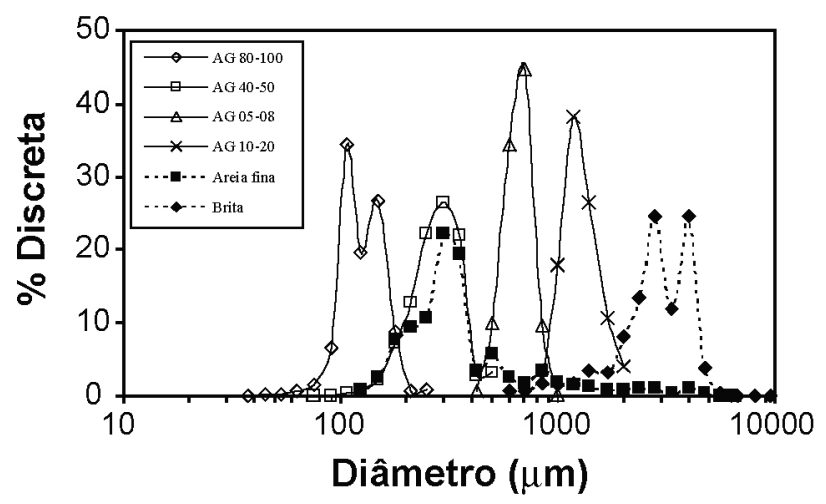

Figura 2: Distribuição granulométrica dos agregados usados na pesquisa. [Figure 2: Particle size distribution of the aggregates used in this research.] 
Tabela II - Massa unitária e massa específica $\left(\mathrm{g} / \mathrm{cm}^{3}\right)$ dos agregados usados na pesquisa.

[Table II - Aggregates' unit weight and specific gravity $\left(\mathrm{g} / \mathrm{cm}^{3}\right)$.]

\begin{tabular}{ccc}
\hline & Massa unitária & Massa específica \\
\hline Brita & 1,49 & 2,87 \\
Areia fina & 1,67 & 2,61 \\
AG 10-20 & 1,48 & 2,62 \\
AG 05-08 & 1,46 & 2,63 \\
AG 40-50 & 1,45 & 2,63 \\
AG 80-100 & 1,43 & 2,64 \\
\hline
\end{tabular}

pós são sílicas moídas e obtidos a partir de matérias-primas de qualidade superior, utilizando avançados equipamentos de última geração tecnológica, a fim de atender as mais exigentes especificações técnicas de mercado. Esses materiais são disponíveis em granulometrias variadas, destinados a produção de tintas, plásticos, borrachas, esmaltes, abrasivos etc.

A sílica MS 920U, utilizada tanto na composição do concreto de referência quanto dos novos concretos, é uma sílica ativa não-densificada obtida a partir da fabricação de silício metálico ou de ligas de ferro-silício. É um material

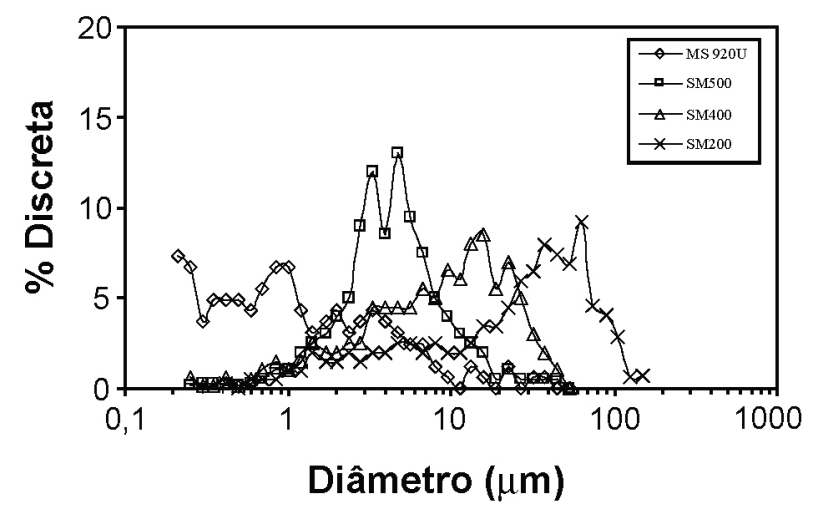

Figura 3: Distribuição granulométrica dos materiais finos usados na pesquisa.

[Figure 3: Particle size distribution of the fine materials used in this research.]
Tabela III - Área superficial e massa específica dos materiais finos usados na pesquisa.

[Table III - Fine materials' superficial area and specific gravity.]

\begin{tabular}{ccc}
\hline & $\begin{array}{c}\text { Área superficial } \\
\left(\text { B.E.T. }-\mathrm{m}^{2} / \mathrm{g}\right)\end{array}$ & $\begin{array}{c}\text { Massa específica } \\
\left(\mathrm{g} / \mathrm{cm}^{3}\right)\end{array}$ \\
\hline SM 200 & 0,758 & 2,72 \\
SM 400 & 1,346 & 2,72 \\
SM 500 & 2,498 & 2,70 \\
MS 920U & 14,270 & 2,42 \\
\hline
\end{tabular}

extremamente fino, constituído de pequenas partículas esféricas com diâmetros médios de cerca de 50 a 100 vezes menores que os diâmetros médios das partículas de cimento, resultando em uma área superficial específica elevada. A sílica apresenta uma composição química consistente, sendo qualificada como quase pura, uma vez que suas partículas possuem altos teores de sílica amorfa quando comparado à presença de pequenas quantidades de outros elementos.

A distribuição granulométrica dos materiais finos utilizados é ilustrada na Fig. 3. As propriedades físicas desses materiais, área superficial e massa específica, são apresentadas na Tabela III.

\section{Composição dos traços de concreto}

\section{Concreto de referência}

O concreto de referência [15] corresponde a um traço de concreto de alto desempenho amplamente adotado em pesquisas destinadas ao desenvolvimento e à aplicação de concretos especiais em obras da construção civil.Écomposto pelo cimento, areia, brita, sílica ativa, superplastificante e água e foi elaborado a partir do estudo inicial das fases que o compõem: pasta de cimento e agregados.

O estudo da matriz pasta de cimento foi realizado para a avaliação da compatibilidade entre os materiais aglomerantes e $\mathrm{o}$ aditivo superplastificante, bem como para

Tabela IV - Composição ideal entre areia e brita (concreto de referência).

[Table IV - Ideal composition between sand and crushed rock (reference concrete).]

\begin{tabular}{ccccccc}
\hline $\begin{array}{c}\text { Composição } \\
\text { brita/areia } \\
(\%)\end{array}$ & $\begin{array}{c}\text { Brita } \\
(\mathrm{kg})\end{array}$ & $\begin{array}{c}\text { Areia } \\
(\mathrm{kg})\end{array}$ & $\begin{array}{c}\text { Acréscimo } \\
\text { de areia }(\mathrm{kg})\end{array}$ & $\begin{array}{c}\text { Massa total } \\
(\mathrm{kg})\end{array}$ & $\begin{array}{c}\text { Massa unitária no } \\
\text { estado compactado } \\
\left(\mathrm{g} / \mathrm{cm}^{3}\right)\end{array}$ & $\begin{array}{c}\text { Índice de } \\
\text { vazios }\end{array}$ \\
\hline 100 & 10,0 & ---- & ---- & 8,230 & 1,668 & 0,72 \\
$90 / 10$ & 10,0 & 1,11 & 1,11 & 8,500 & 1,758 & 0,62 \\
$80 / 20$ & 10,0 & 2,50 & 1,39 & 8,750 & 1,842 & 0,53 \\
$70 / 30$ & 10,0 & 4,28 & 1,78 & 8,990 & 1,922 & 0,45 \\
$60 / 40$ & 10,0 & 6,66 & 2,38 & 9,050 & 1,942 & 0,42 \\
$\mathbf{5 0 / 5 0}$ & $\mathbf{1 0 , 0}$ & $\mathbf{1 0 , 0 0}$ & $\mathbf{3 , 3 4}$ & $\mathbf{9 , 0 5 0}$ & $\mathbf{1 , 9 4 2}$ & $\mathbf{0 , 4 1}$ \\
$40 / 60$ & 10,0 & 15,00 & 5,00 & 8,940 & 1,905 & 0,42 \\
\hline
\end{tabular}


Tabela V - Traço final do concreto de referência.

[Table V - Final mixture proportion for the reference concrete.]

\begin{tabular}{ccccc}
\hline $\begin{array}{c}\text { Traço } \\
(1: a: p)\end{array}$ & Cimento & a/agl & $\begin{array}{c}\text { Teor de } \\
\text { superplastificante }\end{array}$ & $\begin{array}{c}\text { Teor de } \\
\text { sílica ativa }\end{array}$ \\
\hline $1: 1,75: 1,75$ & CPV ARI Plus & 0,40 & $0,61 \%$ & $10 \%$ \\
\hline $\begin{array}{l}\text { a = relação agregado miúdo seco/cimento em massa; } \mathrm{p}=\text { relação agregado graúdo/cimento em massa; } \\
\text { a/agl = relação água/aglomerante. }\end{array}$
\end{tabular}

a determinação do ponto de saturação do aditivo. Pastas que apresentam bons comportamentos no escoamento resultam em concretos com fluidez e consistência satisfatórias.

A fase agregado foi estudada a fim de se buscar o melhor empacotamento entre as partículas mediante a determinação da composição ideal entre elas. Essa composição ideal foi determinada de acordo com o recomendado por Helene e Terzian [16]: dois agregados com distribuições granulométricas distintas são combinados em diversas frações e a massa unitária no estado compactado de cada combinação é determinada de acordo com as especificações da NBR 7810/83 [17]. A composição é considerada ideal quando o valor obtido para a massa unitária é máximo. No caso do concreto de referência, a composição ideal foi determinada entre a areia e a brita (Tabela IV).

Definidas as duas fases que compõem o concreto, a composição final do traço foi realizada. As proporções entre os materiais constituintes da mistura foram determinadas diretamente depois de definidas as características de suas fases constituintes. Um valor para o abatimento foi estabelecido e, caso esse não fosse alcançado, ajustes seriam feitos variando-se o teor de aditivo, uma vez que a quantidade de água de mistura foi mantida constante. $\mathrm{O}$ traço final é apresentado na Tabela V.

A seqüência de incorporação dos materiais constituintes e o procedimento de mistura adotado na produção do concreto de referência foram baseados no processo de mistura amplamente utilizado na prática (Fig. 4). Para a mistura em laboratório utilizando um reômetro, nos três primeiros intervalos desta etapa, a amostra foi misturada sob uma velocidade de rotação de $20 \mathrm{rpm}$, enquanto nos 3 min finais a velocidade de rotação foi aumentada para 60 rpm. O tempo total de mistura foi de 9 min.

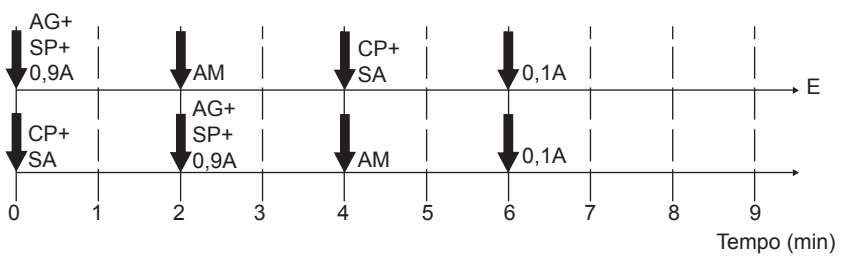

Figura 4: Procedimento de mistura adotado para o concreto de referência, onde $\mathrm{AM}=$ agregado miúdo (areia fina), $\mathrm{AG}=$ agregado graúdo (brita), $\mathrm{CP}=$ cimento, $\mathrm{SA}=$ sílica ativa, $\mathrm{A}=$ água e $\mathrm{SP}=$ superplastificante.

[Figure 4: Mixing procedure for the reference concrete, where AM = fine aggregate (sand), $A G=$ coarse aggregate (crushed rock), $C P$ = cement, $S A=$ silica fume, $A=$ water and $S P=$ superplasticizer. $]$

\section{Novas composições de concreto}

As novas composições foram elaboradas com base nos conceitos de dispersão e empacotamento de partículas, a fim de se obter maior densidade; no entanto, com fluidez adequada. O empacotamento do sistema granular dos concretos foi elaborado utilizando o modelo de Alfred, com coeficiente de distribuição igual a 0,21 e 0,26. A quantidade ótima de aditivo foi definida como aquela que possibilitou atingir índice de fluidez de um concreto auto-adensável, ou seja, maior que $80 \%$.

O procedimento de mistura foi distinto do concreto de referência. Para as novas composições, os materiais secos foram previamente homogeneizados manualmente em sacos plásticos. Em seguida, a água foi adicionada e o material misturado por 1 min na velocidade de rotação de $20 \mathrm{rpm}$. O superplastificante foi adicionado após esse período e a velocidade de rotação foi aumentada para 60 $\mathrm{rpm}$, continuando a mistura por mais $5 \mathrm{~min}$. O tempo total de mistura foi de 6 min.

A resistência mecânica de um material está diretamente relacionada com o tamanho do maior defeito presente no mesmo. Considerando o agregado como tal defeito, quanto menor o tamanho do agregado, maior a resistência mecânica esperada para o material. Além disso, a distribuição do tamanho de grãos influencia tanto a resistência mecânica quanto a reprodutibilidade dos resultados. Embora uma distribuição mais aberta resulte em um melhor empacotamento de partículas do que uma distribuição mais estreita, a reprodutibilidade dos resultados quando se utiliza uma distribuição mais estreita é alta, enquanto que para a distribuição mais aberta a reprodutibilidade pode ser menor. Assim, nessa primeira etapa do desenvolvimento da pesquisa, agregados com dimensões menores foram utilizados a fim de se aumentar a resistência mecânica por meio da redução do tamanho do maior defeito e, conseqüentemente, aumentar a reprodutibilidade dos resultados. Sendo assim, a dimensão máxima do agregado foi limitada em $2 \mathrm{~mm}$.

\section{Procedimento experimental}

O procedimento experimental constituiu da definição dos traços das novas composições de concreto e da avaliação das propriedades tanto no estado fresco quanto no estado endurecido. $\mathrm{O}$ esquema geral do estudo experimental é apresentado na Fig. 5. 


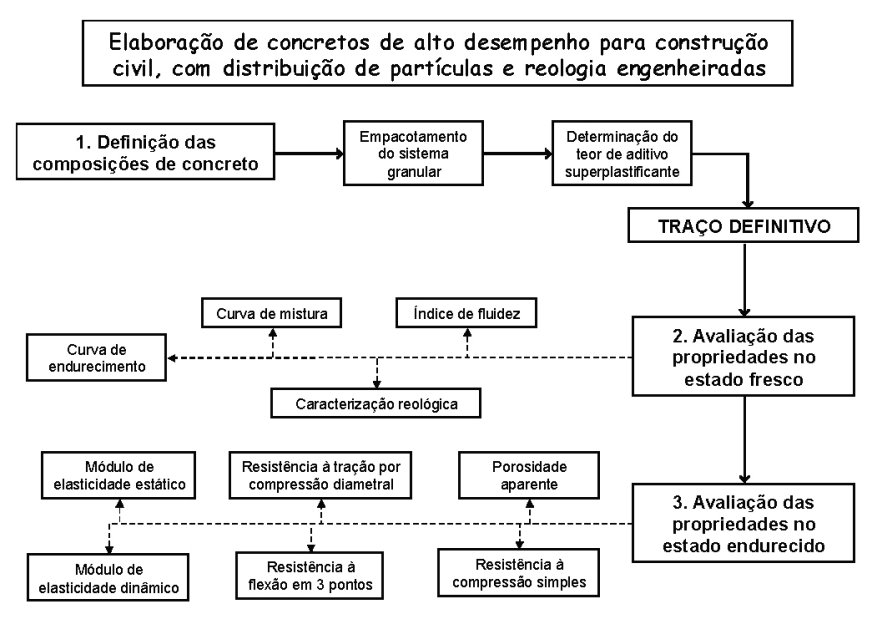

Figura 5: Esquema do procedimento experimental usado na presente pesquisa.

[Figure 5: Schematic representation of the experimental procedure used in this research.]

\section{Avaliação das propriedades no estado fresco}

A avaliação das propriedades no estado fresco compreendeu a medida do índice de fluidez da mistura e a determinação de suas propriedades reológicas.

Para a medida do índice de fluidez, uma amostra de concreto foi colocada em um molde tronco-cônico metálico com diâmetro superior de $70 \mathrm{~mm}$, diâmetro inferior $100 \mathrm{~mm}$ e altura $65 \mathrm{~mm}$ e, após corretamente nivelado, foi retirado verticalmente. Dois diâmetros ortogonais da amostra foram medidos e o índice de fluidez determinado pela equação B.

$$
\text { Fluidez }=100\left[\frac{\mathrm{D}_{\mathrm{esp}}-\mathrm{D}_{\mathrm{inf}}}{\mathrm{D}_{\mathrm{inf}}}\right]
$$

onde $\mathrm{D}_{\text {esp }}$ é o diâmetro médio do espalhamento e $\mathrm{D}_{\text {inf }} \mathrm{o}$ diâmetro inferior do molde tronco-cônico. $\mathrm{O}$ índice de fluidez foi medido para duas condições: apenas sob a ação da gravidade (free flow) e sob a influência de uma força vibratória (vibra flow). As curvas de mistura dos concretos foram plotadas e a energia de mistura imposta pelo misturador foi determinada como a área sob a curva do torque versus tempo. Assim, foi possível verificar a eficiência desta etapa para cada composição.

A caracterização reológica dos concretos foi realizada por meio de ensaios de cisalhamento executados com o auxílio de um reômetro. Para isso, as amostras foram submetidas a ciclos de cisalhamento em escada, com velocidade de rotação variando entre $5 \mathrm{rpm}$ e $80 \mathrm{rpm}$ após a mistura. Esse tipo de ensaio gera curvas de cisalhamento que permitem identificar o tipo de comportamento reológico apresentado pelo concreto, verificar uma possível tixotropia no material e a eficiência do procedimento de mistura adotado.

Para a identificação do comportamento reológico, as curvas de cisalhamento (tanto a parte ascendente quanto a parte descendente) foram ajustadas por dois modelos reológicos: Bingham e lei das potências. Assim, o comportamento reológico da mistura foi identificado pelo modelo que melhor se ajustou à curva de cisalhamento, ou seja, aquele que permitiu obter o maior coeficiente de correlação entre os dados obtidos pelo reômetro e a reta constitutiva do modelo reológico. O acompanhamento das propriedades reológicas foi feito por um intervalo de até 1 $\mathrm{h}$ após o contato água-cimento. Assim, foi possível verificar a perda de trabalhabilidade e das demais propriedades por meio da evolução dos parâmetros reológicos, tensão de escoamento e viscosidade plástica.

A avaliação do comportamento de concretos sob uma taxa de cisalhamento contínua, ou mais precisamente, sob uma velocidade de rotação constante constitui uma técnica alternativa às curvas de cisalhamento. Assim, o processo de endurecimento das misturas também foi acompanhado durante o período compreendido desde o fim da mistura até a total perda de trabalhabilidade do material (falta de coesão da amostra).

\section{Avaliação das propriedades no estado endurecido}

A avaliação das propriedades no estado endurecido compreendeu a medida da porosidade aparente, da resistência mecânica e do módulo de elasticidade. A relação completa dos ensaios realizados, bem como os métodos de ensaio adotados, é apresentada a seguir: porosidade aparente [18]; resistência à compressão simples de corpos de prova cilíndricos [19]; resistência à tração por compressão diametral de corpos de prova cilíndricos [20]; resistência à flexão em três pontos de corpos de prova prismáticos [21]; módulo de elasticidade estático em corpos de prova cilíndricos [22]; módulo de elasticidade dinâmico em corpos de prova prismáticos [23].

O módulo de elasticidade estático corresponde à inclinação da curva tensão versus deformação obtida quando um corpo de prova cilíndrico de concreto é submetido a um carregamento uniaxial de compressão com velocidade controlada. De acordo com o modelo utilizado na sua determinação, o módulo de elasticidade estático pode ser tangente ou secante [24]. A qualidade e a reprodutibilidade apresentadas nos resultados dos ensaios experimentais dinâmicos fazem com que este seja um parâmetro global, obtido de maneira integrada e com um alto grau de confiabilidade [24]. O método de ensaio utilizado para a determinação do módulo de elasticidade dinâmico mede a frequiência de ressonância de corpos de prova prismáticos de concreto, excitando-os mecanicamente por meio de uma haste elástica e um equipamento de impulso. Um transdutor sente as vibrações mecânicas resultantes da amostra e as transforma em sinais elétricos. O apoio da amostra, os locais do impulso e os picos dos sinais são selecionados para induzir e medir modos específicos de vibrações transitórias. Os sinais são analisados e a freqüência de ressonância é isolada e medida por um analisador de sinal, que possibilita uma leitura numérica que pode ser (ou ser proporcional a) tanto a frequiência quanto o período de vibração da amostra. 
A freqüência de ressonância, as dimensões e a massa do corpo de prova são usadas para calcular, além do módulo de elasticidade dinâmico, o módulo de cisalhamento dinâmico e o coeficiente de Poisson [23].

Os corpos de prova cilíndricos e prismáticos foram moldados em dimensões de $40 \mathrm{~mm}$ x $40 \mathrm{~mm}$ e $25 \mathrm{~mm}$ x 25 $\mathrm{mm}$ x $150 \mathrm{~mm}$, respectivamente. O método de cura adotado foi a úmido por imersão em água saturada com cal, onde os corpos de prova permaneceram até as idades de ensaio: 1 , $3,7,11,15,19,23$ e 28 dias. Para os ensaios de resistência à compressão simples e módulo de elasticidade estático, as superfícies dos corpos de prova cilíndricos foram retificadas para redução das irregularidades existentes.

\section{RESULTADOS E DISCUSSÃO}

\section{Composições de concreto}

Apesar de ter sido dosado de uma maneira que considera os conceitos de empacotamento de partículas, a distribuição granulométrica do concreto de referência foi inserida no programa computacional que determina o empacotamento do sistema granular de um concreto e a curva de distribuição das partículas resultante é apresentada na Fig. 6. O coeficiente de distribuição resultante foi igual a 0,33 .

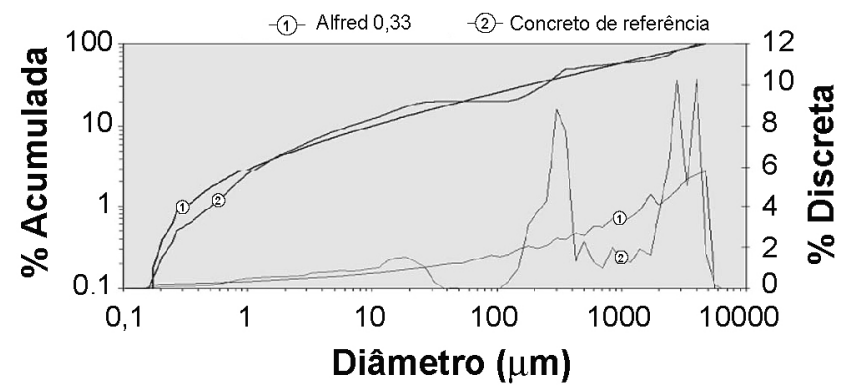

Figura 6: Curva da distribuição granulométrica do concreto de referência, $\mathrm{q}=0,33$. ( $\mathrm{R}^{2}$ acumulado 0,$0806 ; \mathrm{R}^{2}$ discreto 0,0199$)$.

[Figure 6: Particle size distribution for the reference concrete, $q=0.33 .\left(R^{2}\right.$ accumulated 0.0806; $R^{2}$ discreet 0.0199).]

Como mencionado anteriormente, as novas composições de concreto foram feitas com base nos conceitos computacionais de empacotamento e dispersão de partículas. $\mathrm{O}$ estudo do empacotamento do sistema granular dos novos concretos foi feito a partir do modelo de Alfred, onde dois valores foram adotados para o coeficiente de distribuição $(q): 0,21$ e 0,26 . As curvas de distribuição dos concretos, para cada coeficiente de distribuição, são apresentadas nas Figs. 7 e 8.

As quantidades de cada matéria-prima determinadas pelo estudo de empacotamento realizado para cada coeficiente de distribuição são apresentadas na Tabela VI.

Definido o sistema de partículas que compõe cada mistura $(q=0,21$ e $q=0,26)$, o estudo para determinação do teor ótimo de aditivo superplastificante foi realizado. Foram feitas sucessivas adições de aditivo até que o índice de fluidez livre (free flow) medido fosse maior ou igual ao índice de fluidez

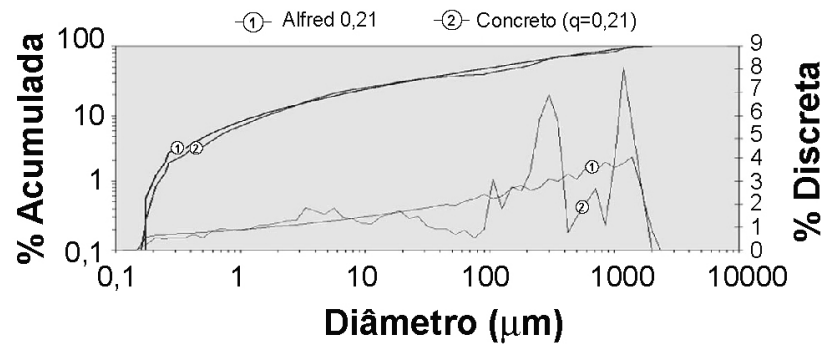

Figura 7: Curva da distribuição granulométrica da composição de concreto, para $\mathrm{q}=0,21$. ( $\mathrm{R}^{2}$ acumulado 0,$0629 ; \mathrm{R}^{2}$ discreto 0,0088$)$.

[Figure 7: Particle size distribution for the concrete with $q=0.21$. $\left(R^{2}\right.$ accumulated 0.0629; $R^{2}$ discreet 0.0088).]

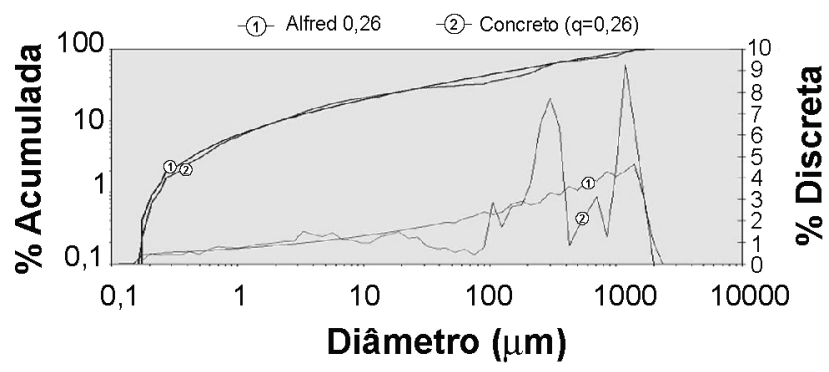

Figura 8: Curva da distribuição granulométrica da composição de concreto, para $\mathrm{q}=0,26$. ( $\mathrm{R}^{2}$ acumulado 0,$0935 ; \mathrm{R}^{2}$ discreto 0,0110$)$.

[Figure 8: Particle size distribution for the concrete with $q=0.26 .\left(R^{2}\right.$ accumulated 0.0935; $R^{2}$ discreet 0.0110).]

Tabela VI - Proporção entre as matérias-primas das misturas de concreto estudadas.

[Table VI - Raw materials content for the concretes analyzed.]

\begin{tabular}{cccc}
\hline Matéria-prima & $\begin{array}{c}q=0,21 \\
\% \mathrm{p}\end{array}$ & $\begin{array}{c}q=0,26 \\
\% \mathrm{p}\end{array}$ & $\begin{array}{c}q=0,33 \text { (REF) } \\
\% \mathrm{p}\end{array}$ \\
\hline Brita & ----- & ----- & 39 \\
Areia fina & ----- & ----- & 38 \\
AG 10-20 & 21 & 24 & ---- \\
AG 05-08 & 6 & 7 & ---- \\
AG 40-50 & 26 & 29 & ---- \\
AG 80-100 & 8 & 7,5 & ---- \\
SM 200 & 9 & 7 & ---- \\
SM 400 & 4 & 3 & ---- \\
SM 500 & 4 & 2,5 & ---- \\
MS 920U & 12 & 10 & 1,4 \\
CPV ARI Plus & 10 & 10 & 20,8 \\
\hline
\end{tabular}

de um concreto auto-adensável, isto é, $80 \%$. A quantidade de água foi mantida fixa em 7\% para ambas as composições e os teores ótimos de aditivo determinados para os concretos com $\mathrm{q}=0,21$ e $\mathrm{q}=0,26$ foram iguais a $0,75 \%$ e $0,65 \%$, respectivamente. Vale lembrar que as quantidades de água e de superplastificante são determinadas para a quantidade total de material e não apenas sobre a quantidade de cimento e/ou aglomerante (cimento e sílica ativa). 


\section{Propriedades do concreto no estado fresco}

\section{Curvas de mistura}

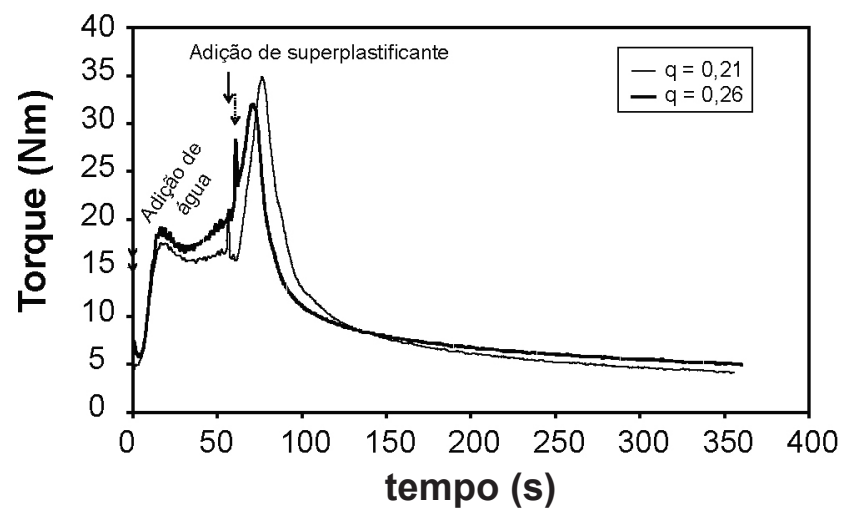

Figura 9: Curva de mistura das novas composições de concreto. [Figure 9: Mixing curve of the new compositions of concrete.]

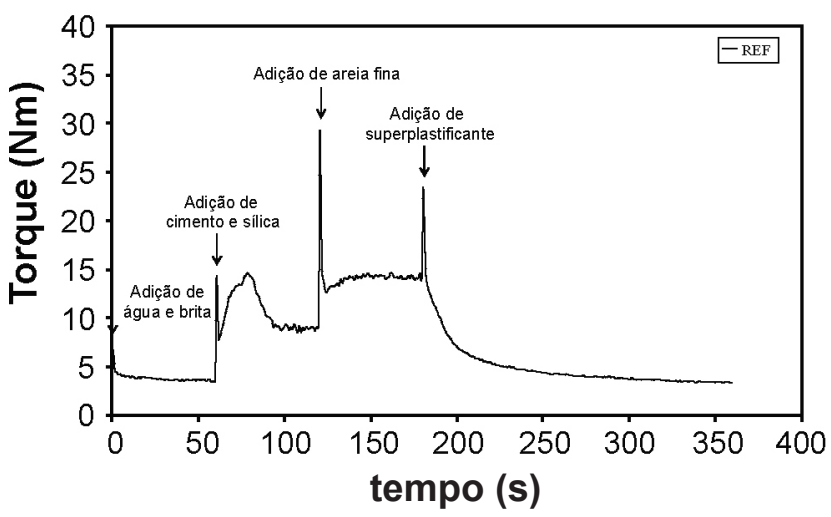

Figura 10: Curva de mistura do concreto de referência. Obs.: para a construção do gráfico, os intervalos em que a amostra permaneceu em repouso foram desconsiderados.

[Figure 10: Mixing curve of the reference concrete. Obs.: for the mixing profile, the time intervals where the sample stayed in rest were not included.]

Considerando-se as Figs. 9 e 10, verifica-se que o concreto de referência e as novas composições de concreto apresentam curvas de misturas distintas com relação ao seu formato, uma vez que a seqüência de incorporação dos materiais constituintes da mistura não é a mesma.

Como a eficiência de uma mistura é dada pela área sob a curva de mistura, verifica-se, a partir dos valores calculados

Tabela VII - Área sob a curva de mistura de cada concreto estudado.

[Table VII - Area under the mixing curve for each studied concrete.]

\begin{tabular}{cc}
\hline Concreto & Área (Nm.s) \\
\hline 0,21 & 3354 \\
0,26 & 3522 \\
REF & 2595 \\
\hline
\end{tabular}

(Tabela VII), que a área do concreto de referência é menor que a área das outras duas misturas. A diferença observada pode ser atribuída à presença de agregados com diâmetros maiores (brita) na composição do concreto de referência. Esses agregados auxiliam na quebra dos aglomerados, liberando a água aprisionada e melhorando sua distribuição entre as partículas. À medida que a dimensão dos agregados diminui, esse efeito de moagem é reduzido, aumentando a energia necessária para a mistura do material. Além disso, a mistura seqüencial com intervalos de repouso também pode ter contribuído para esse resultado.

Para constatar a influência do procedimento de mistura sobre sua eficiência, as novas composições de concreto também foram preparadas de acordo com o procedimento de mistura estabelecido para o concreto de referência. Sendo assim, as areias (AG 10-20, AG 05-08, AG 40-50 e AG 80-100) foram adicionadas como sendo equivalentes ao agregado graúdo da mistura de referência, enquanto os pós de quartzo (SM 200, SM 400 e SM 500) foram adicionados como sendo equivalentes ao agregado miúdo da mesma mistura. As curvas de mistura das novas composições de concreto segundo o procedimento de mistura estabelecido para o concreto de referência são apresentadas na Fig. 11.

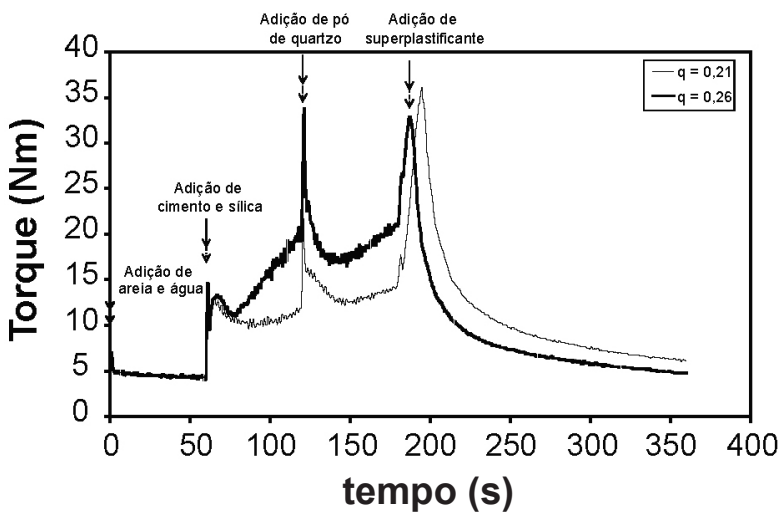

Figura 11: Curvas de mistura das novas composições de concreto produzidas de acordo com o procedimento de mistura do concreto de referência. Obs.: para a construção do gráfico, os intervalos em que a amostra permaneceu em repouso foram desconsiderados.

[Figure 11: Mixing curves of the new compositions of concrete produced according to the reference concrete mixing procedure. Obs.: for the mixing profile, the time intervals where the sample stayed in rest were not included.]

A produção das novas composições de concreto de acordo com o procedimento de mistura do concreto de referência implicou em maiores áreas sob a curva de mistura: respectivamente 3738 Nm.s e 3917 Nm.s para os concretos com coeficiente de distribuição igual a 0,21 e 0,26 , indicando que esse procedimento é menos eficiente do que o adotado. Além disso, as novas composições de concreto consideradas auto-adensáveis, quando produzidas segundo o procedimento do concreto de referência, apresentaram baixíssimos índices de fluidez livre, sendo possível observar um adensamento adequado apenas quando a vibração foi aplicada. Em termos de reologia, verificaram-se maiores tensões de escoamento quando o procedimento de mistura 
foi alterado, porém a viscosidade plástica praticamente não foi influenciada.

\section{Índice de fluidez}

Normalmente, um coeficiente de distribuição acima de 0,30 favorece a produção de concretos adensados sob vibração, enquanto valores menores que 0,28 resultam em misturas auto-adensáveis; o efeito da redução do valor do coeficiente de distribuição se dá no aumento da quantidade de finos, o que influencia a interação entre as partículas [25]. Esse fato é verificado nas misturas estudadas: as novas composições de concreto $(\mathrm{q}=0,21$ e 0,26$)$ apresentaram um comportamento semelhante ao de um material autoadensável, enquanto o concreto de referência $(\mathrm{q}=0,33)$ só pode ser adensado adequadamente com a aplicação de vibração, mesmo possuindo um tamanho máximo de partícula superior (Tabela VIII).

Tabela VIII - Valores dos índices de fluidez medidos sem e com ação de uma força vibratória.

[Table VIII - Values of fluidity index measured with and without vibration.]

\begin{tabular}{ccc}
\hline Concreto & Free flow (\%) & Vibra flow $(\%)$ \\
\hline 0,21 & 80 & 126 \\
0,26 & 89 & 122 \\
REF & 0 & 185 \\
\hline
\end{tabular}

A forma das partículas dos agregados usados na composição das novas misturas de concretos se aproxima de uma esfera, o que facilita o movimento relativo entre elas durante o escoamento. Por outro lado, a forma das partículas de brita que compõe o concreto de referência é mais lamelar, o que pode resultar no imbricamento mecânico entre elas e, assim, dificultar o escoamento do material sob influência apenas do seu peso próprio. No entanto, o superior tamanho do agregado contribui para um superior valor do índice de fluidez sob vibração.

\section{Curvas de cisalhamento}

Para a construção das curvas de cisalhamento, a velocidade foi considerada em rotação por segundo (rps) para que o parâmetro relacionado com a viscosidade plástica (viscosidade de torque $h$ ), expresso em Nm.s, fosse determinado diretamente. Caso contrário, ao plotar as curvas de cisalhamento com a velocidade de rotação em rpm, esse parâmetro deveria ser corrigido na equação da reta.

A partir das curvas de cisalhamento, verifica-se que a parte ascendente e a parte descendente não coincidem, resultando na formação de uma área de histerese. Essa área representa o trabalho relacionado com o volume cisalhado, possibilitando uma análise qualitativa e, assim, tirar conclusões quanto à estabilidade da estrutura desses materiais [26]. Inicialmente, esse comportamento indica que

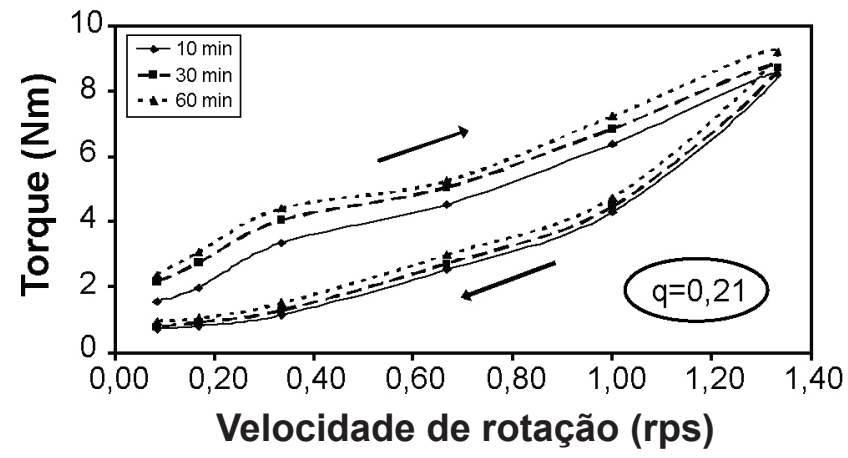

Figura 12: Curva de cisalhamento do concreto com q =0,21. Obs.: As setas indicam o sentido de aplicação da velocidade de cisalhamento.

[Figure 12: Flow curve of the concrete with $q=0.21$. Obs.: the arrows indicate the up and down curves, respectively.]

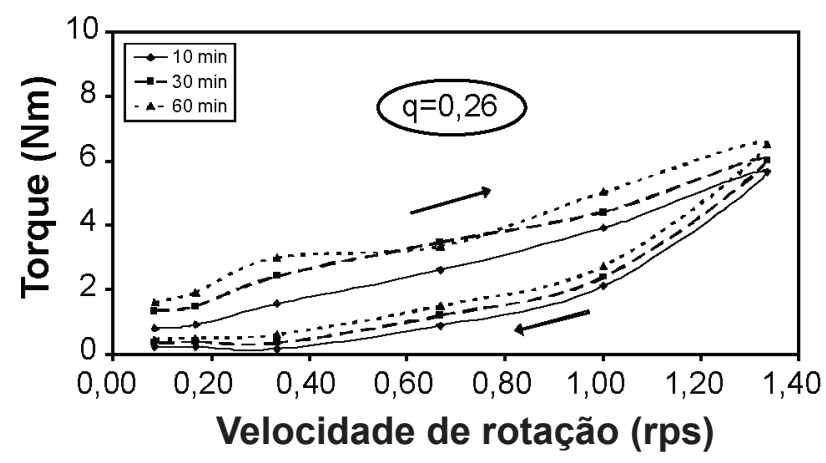

Figura 13: Curva de cisalhamento do concreto com $q=0,26$. Obs.: As setas indicam o sentido de aplicação da velocidade de cisalhamento.

[Figure 13: Flow curve of the concrete with $q=0.26$. Obs.: the arrows indicate the up and down curves, respectively.]

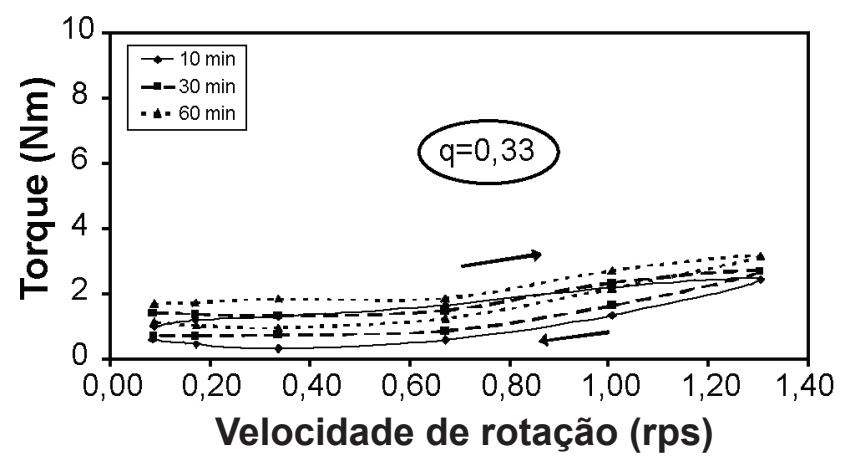

Figura 14: Curva de cisalhamento do concreto de referência. Obs.: As setas indicam o sentido de aplicação da velocidade de cisalhamento.

[Figure 14: Flow curve of the reference concrete. Obs.: the arrows indicate the up and down curves, respectively.]

o misturador não foi capaz de fornecer energia suficiente para quebrar os aglomerados presentes na mistura; assim, um processo de mistura mais eficiente está relacionado com uma menor área de histerese. Além disso, a não coincidência das partes ascendente e descendente da curva de cisalhamento evidencia o comportamento tixotrópico dos concretos.

Os valores das áreas de histerese geradas são apresentados na Tabela IX. Verifica-se que os valores variam em função da composição do concreto. Mais uma vez, é possível verificar a influência dos agregados com diâmetros maiores sobre 
Tabela IX - Área de histerese das curvas de cisalhamento dos concretos estudados - unidade: Nm.rps.

[Table IX - Hysteresis area for the concretes' flow curves unity: Nm.rps.]

\begin{tabular}{cccc}
\hline \multirow{2}{*}{ Concreto } & \multicolumn{3}{c}{ Tempo de medida (min) } \\
& 10 & 30 & 60 \\
\hline 0,21 & 2,51 & 2,99 & 3,13 \\
0,26 & 1,95 & 2,50 & 2,62 \\
REF & 0,69 & 0,66 & 0,58 \\
\hline
\end{tabular}

a quebra dos aglomerados e, conseqüentemente, sobre a eficiência de mistura do material: a área de histerese gerada para o concreto de referência foi bem menor do que as áreas geradas para as novas composições.

\section{Caracterização reológica}

Para a identificação do comportamento reológico das misturas de concreto, os ajustes foram feitos tanto na parte ascendente quanto na parte descendente da curva de cisalhamento, sendo utilizados dois modelos - Bingham e

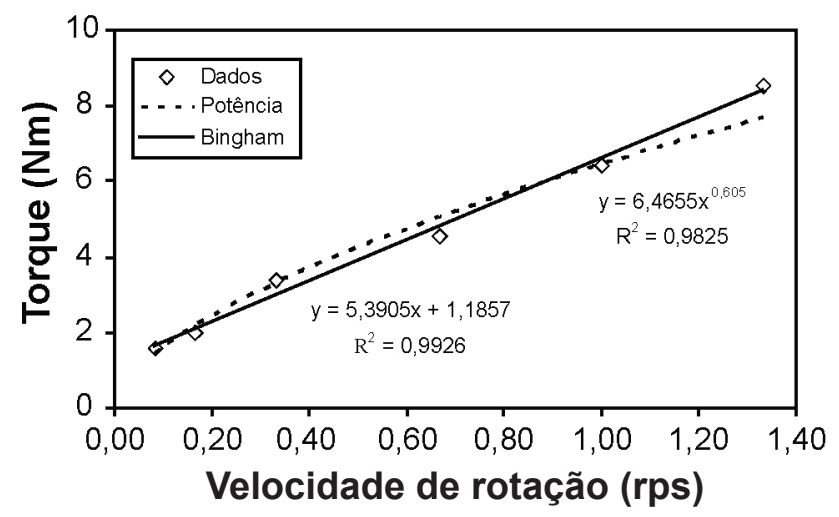

Figura 15: Parte ascendente da curva de cisalhamento do concreto com $\mathrm{q}=0,21$.

[Figure 15: Shearing upward plot for the concrete with $q=0.21$.]

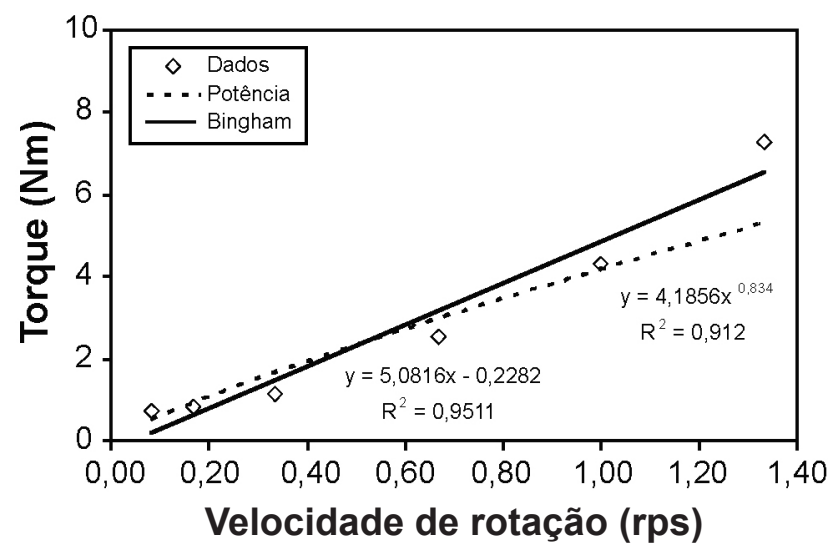

Figura 16: Parte descendente da curva de cisalhamento do concreto com q $=0,21$.

[Figure 16: Shearing downward plot for the concrete with $q=0.21$.] lei das potências. A partir dos resultados obtidos (Figs. 15, $16,17,18,19$ e 20 ), a consideração da parte ascendente da curva de cisalhamento se mostrou mais adequada (maiores coeficientes de correlação), além de corresponder ao período em que a tensão de escoamento deve ser excedida para que o material inicie seu escoamento.

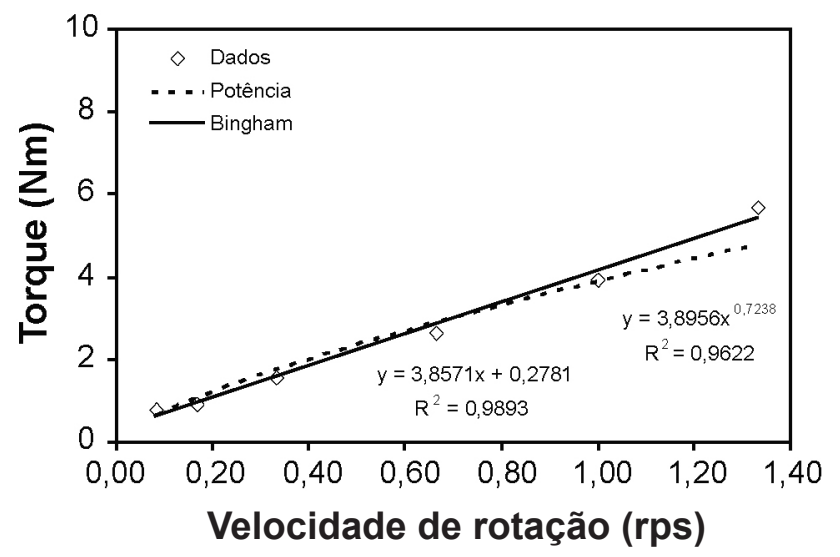

Figura 17: Parte ascendente da curva de cisalhamento do concreto com $\mathrm{q}=0,26$.

[Figure 17: Shearing upward plot for the concrete with $q=0.26$.]

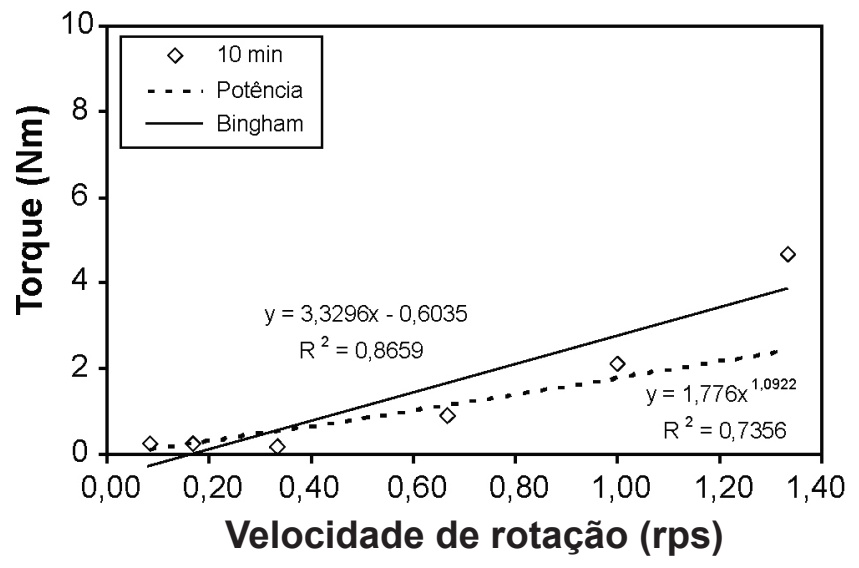

Figura 18: Parte descendente da curva de cisalhamento do concreto com $\mathrm{q}=0,26$.

[Figure 18: Shearing downward plot for the concrete with $q=0.26$. .]

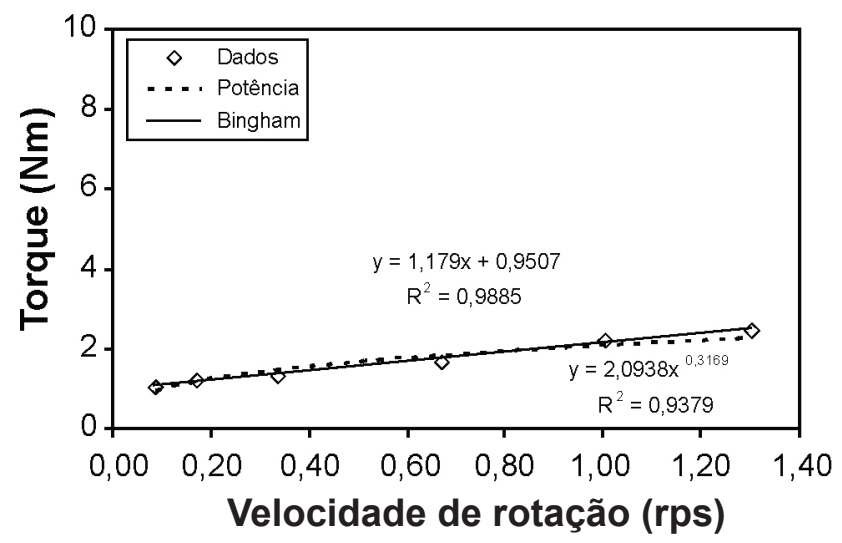

Figura 19: Parte ascendente da curva de cisalhamento do concreto de referência.

[Figure 19: Shearing upward plot for the reference concrete.] 


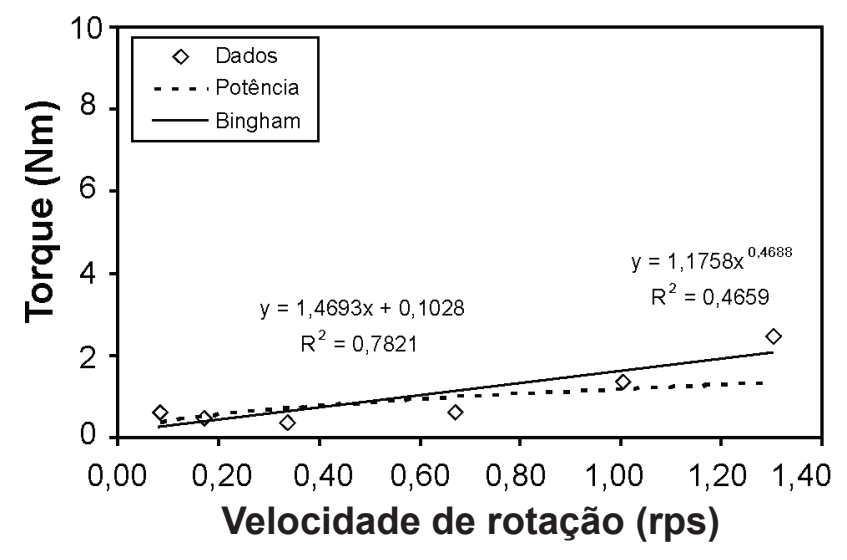

Figura 20: Parte descendente da curva de cisalhamento do concreto de referência.

[Figure 20: Shearing downward plot for the reference concrete.]

O comportamento reológico de todas as misturas estudadas se ajustaram melhor ao modelo binghamiano, ou seja, o ajuste da parte ascendente da curva de cisalhamento a esse modelo resultou nos maiores valores para o coeficiente de correlação entre a curva e a reta constitutiva. Este comportamento é amplamente observado para as misturas de concreto de alto desempenho estudadas nos grandes centros de pesquisa da tecnologia dos concretos e encontradas na literatura. Como em reologia os parâmetros que caracterizam o comportamento desses materiais são dependentes do equipamento utilizado no ensaio, eles normalmente são expressos em unidades de torque. Assim, nesse trabalho, a tensão de escoamento e a viscosidade plástica são apresentadas como torque de escoamento $(g) \mathrm{e}$ viscosidade de torque $(h)$, respectivamente.

Para o acompanhamento da evolução das propriedades reológicas ao longo do tempo, as amostras de concreto foram submetidos a ciclos de cisalhamento 10,30 e $60 \mathrm{~min}$ após o contato água-cimento, sendo feita a determinação dos parâmetros reológicos para cada tempo de medida. Assim, a partir dos valores apresentados na Tabela $X$, verifica-se que o torque de escoamento aumenta com o decorrer do tempo,

Tabela X - Valores dos parâmetros reológicos considerandose a parte ascendente da curva de cisalhamento e comportamento binghamiano.

[Table X - Values of the rheological parameters considering upward part of the flow curve and the Bingham behavior.]

\begin{tabular}{ccccccc}
\hline & \multicolumn{3}{c}{$\begin{array}{c}\text { Torque de } \\
\text { escoamento } \\
\text { Concreto }\end{array}$} & \multicolumn{3}{c}{$\begin{array}{c}\text { Viscosidade de } \\
\text { torque }[h(\mathrm{Nm} . \mathrm{s})]\end{array}$} \\
\cline { 2 - 7 } & \multicolumn{3}{c}{$\begin{array}{c}\text { Tempo de medida } \\
\text { (min) }\end{array}$} & \multicolumn{3}{c}{$\begin{array}{c}\text { Tempo de medida } \\
\text { (min) }\end{array}$} \\
\hline 0,21 & 10 & 30 & 60 & 10 & 30 & 60 \\
\hline 0,26 & 0,28 & 1,01 & 1,34 & 3,86 & 3,68 & 3,77 \\
$\mathrm{REF}$ & 0,95 & 1,13 & 1,48 & 1,18 & 1,12 & 1,19 \\
\hline
\end{tabular}

enquanto a viscosidade permanece praticamente constante. $\mathrm{O}$ aumento da tensão de escoamento de um concreto ao longo do tempo reflete o processo de endurecimento desse material; porém, não a evolução da viscosidade plástica. Como as amostras de concreto permanecem em repouso entre os consecutivos ensaios reológicos, a exigência de torque para as baixas velocidades de rotação aumenta mais do que para as velocidades mais altas, provavelmente devido à aglomeração das partículas, à geração dos produtos da hidratação e ao esgotamento das moléculas de superplastificante no processo químico. Isso resulta em uma redução da inclinação da curva de cisalhamento, o que pode explicar porque a viscosidade plástica não aumenta com o tempo, tendendo a diminuir ligeiramente em alguns casos [27].

\section{Curvas de endurecimento}

O comportamento ao cisalhamento dos concretos foi acompanhado ao longo do tempo. Para isso, as amostras foram submetidas a um cisalhamento contínuo (velocidade de rotação constante e igual a $25 \mathrm{rpm}$ ) no reômetro por um período de tempo indefinido, isto é, até que o torque limite de segurança do equipamento fosse atingido ou que a mistura se apresentasse sem coesão (pá misturadora girando no vazio). As curvas resultantes são apresentadas na Fig. 21. Vale lembrar que as curvas experimentais foram suavizadas para a redução do ruído e melhor visualização das tendências de endurecimento das misturas.

$\mathrm{O}$ processo de pega e endurecimento do concreto de referência se deu de maneira contínua e gradual até o fim do ensaio, caracterizado pela perda de coesão do material. Por outro lado, as novas composições de concreto conseguiram se manter trabalháveis por um longo período de tempo - as amostras foram mantidas sob cisalhamento por até quatro horas após o contato inicial entre o cimento e a água de mistura, quando o ensaio foi interrompido; até esse momento, nem o torque de segurança $(65 \mathrm{Nm})$ tinha sido atingido, nem a falta de coesão tinha sido verificada no material. Isso mostra que os concretos projetados podem apresentar maior trabalhabilidade sem a necessidade da adição de aditivos

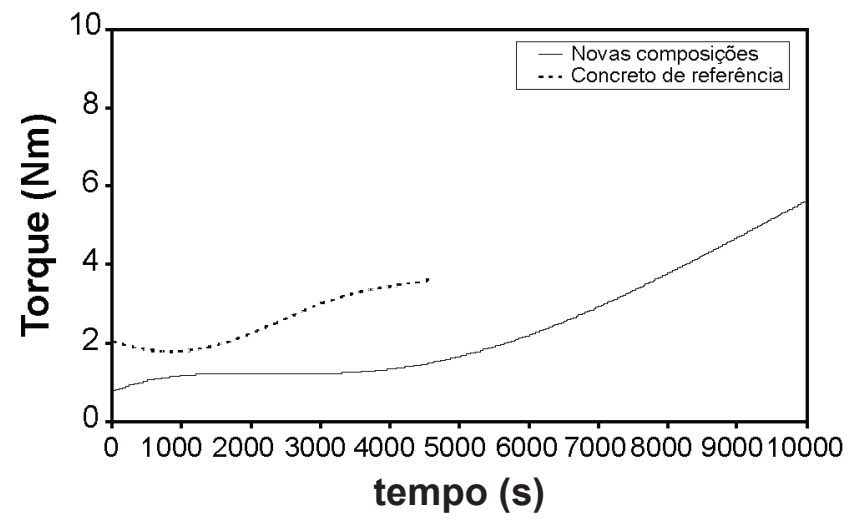

Figura 21: Curvas de endurecimento dos concretos estudados. [Figure 21: Hardening curves of the studied concretes.] 
retardadores que afetam a resistência mecânica.

\section{Porosidade aparente}

Quando o grau de hidratação é pequeno (primeiras idades), a influência da densidade de empacotamento sobre a porosidade prevalece, enquanto o efeito do grau de hidratação é secundário. Quando o grau de hidratação é maior (idades mais avançadas), tanto a densidade de empacotamento quanto o grau de hidratação influenciam a porosidade simultaneamente. Assim, do ponto de vista da porosidade, as influências da densidade de empacotamento e do grau de hidratação devem ser consideradas cooperativamente, indicando que uma distribuição granulométrica mais ampla é mais vantajosa para se obter uma mistura com uma menor porosidade [28].

Os efeitos da densidade de empacotamento e do grau de hidratação podem ser observados nas misturas estudas. Nas primeiras idades, o concreto de referência, que possui um coeficiente de distribuição maior, apresenta uma porosidade aparente intermediária; porém, ao longo do tempo, com o desenvolvimento da hidratação do cimento, os novos concretos desenvolvem matrizes mais densas, resultando em uma porosidade aparente aproximadamente $50 \%$ menor que o concreto de referência.

\section{Propriedades do concreto no estado endurecido}

\section{Resistência mecânica}

A evolução do desempenho mecânico das misturas é semelhante para as três resistências medidas (compressão, tração e flexão): nas primeiras idades, o concreto de referência apresenta o melhor desempenho mecânico, resultando em maior resistência; porém, ao longo do tempo, os novos concretos são superiores, ou seja, superiores resistências à compressão, à tração e à flexão. As maiores resistências iniciais do concreto de referência podem ser associadas à presença de agregados graúdos (britas de origem basáltica), os quais contribuem com o desempenho mecânico. Como a resistência diminui com o aumento do tamanho dos poros e aumenta com a diminuição do tamanho do grão, ao longo do

Tabela XI - Valores da porosidade aparente (\%) dos concretos estudados.

[Table XI - Values of apparent porosity (\%) for the studied concretes.]

\begin{tabular}{ccccccc}
\hline Concreto & \multicolumn{2}{c}{0,21} & \multicolumn{2}{c}{0,26} & \multicolumn{2}{c}{ REF } \\
\hline Idade (dias) & Porosidade & Desvio & Porosidade & Desvio & Porosidade & Desvio \\
\hline 1 & 1,77 & 0,61 & 3,59 & 0,60 & 2,68 & 0,14 \\
3 & 1,01 & 0,22 & 1,56 & 0,22 & 1,24 & 0,24 \\
7 & 0,43 & 0,09 & 0,59 & 0,18 & 0,77 & 0,13 \\
11 & 0,47 & 0,04 & 0,63 & 0,05 & 0,75 & 0,06 \\
15 & 0,35 & 0,05 & 0,21 & 0,06 & 0,60 & 0,06 \\
19 & 0,34 & 0,03 & 0,29 & 0,04 & 0,74 & 0,04 \\
23 & 0,34 & 0,07 & 0,34 & 0,07 & 0,73 & 0,11 \\
28 & 0,28 & 0,08 & 0,24 & 0,04 & 0,68 & 0,10 \\
\hline
\end{tabular}

Obs.: Os valores apresentados correspondem à média de 5 determinações

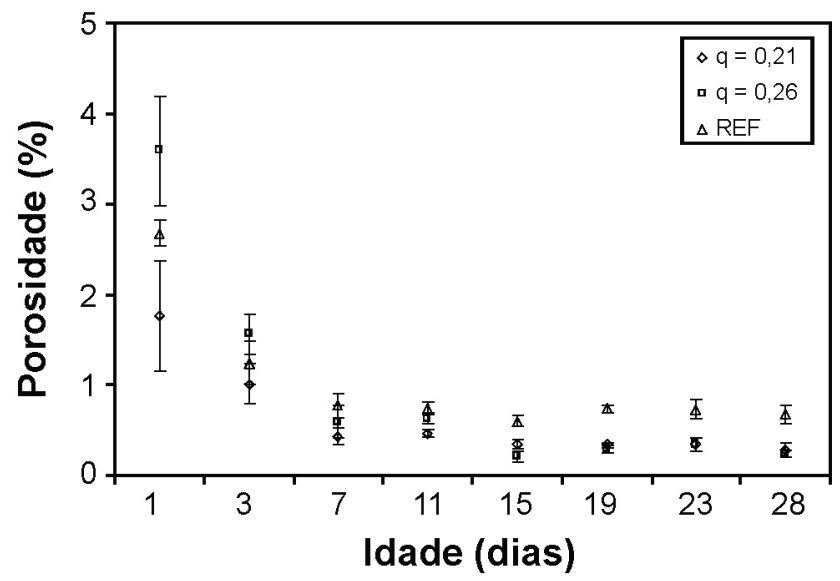

Figura 22: Evolução da porosidade aparente dos concretos ao longo do tempo.

[Figure 22: Evolution of the concretes' apparent porosity with the time.] 
Tabela XII - Valores da resistência à compressão uniaxial (MPa) dos concretos estudados. [Table XII - Values of compressive strength (MPa) for the studied concretes.]

\begin{tabular}{ccccccc}
\hline Concreto & \multicolumn{2}{c}{0,21} & \multicolumn{2}{c}{0,26} & \multicolumn{2}{c}{ REF } \\
\hline Idade (dias) & Resistência & Desvio & Resistência & Desvio & Resistência & Desvio \\
\hline 1 & 17,1 & 1,1 & 13,9 & 0,9 & 39,2 & 2,6 \\
3 & 42,0 & 2,5 & 38,6 & 2,0 & 60,9 & 5,2 \\
7 & 69,9 & 0,4 & 67,3 & 2,7 & 60,2 & 5,0 \\
11 & 81,9 & 3,0 & 86,7 & 2,2 & 67,6 & 2,6 \\
15 & 95,1 & 5,1 & 97,9 & 3,5 & 76,9 & 5,2 \\
19 & 103,3 & 2,1 & 103,4 & 4,8 & 80,5 & 2,4 \\
23 & 111,4 & 5,4 & 104,2 & 5,8 & 82,7 & 4,8 \\
28 & 111,9 & 5,8 & 112,8 & 6,4 & 79,6 & 2,2 \\
\hline
\end{tabular}

Obs.: Os valores apresentados correspondem à média de 5 determinações.

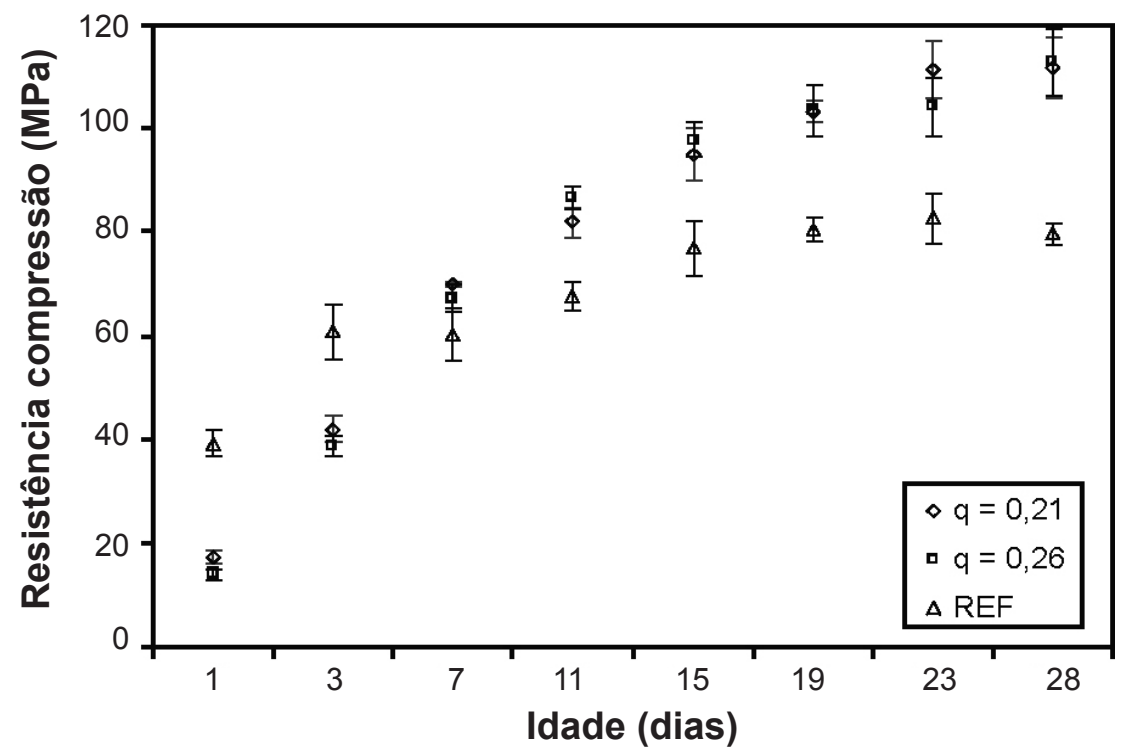

Figura 23: Evolução da resistência à compressão uniaxial dos concretos ao longo do tempo. [Figure 23: Evolution of the concretes' compressive strength with the time.]

Tabela XIII - Valores da resistência à tração por compressão diametral (MPa) dos concretos estudados. [Table XIII - Values of splitting tensile strength (MPa) for the studied concretes.]

\begin{tabular}{ccccccc}
\hline Concreto & \multicolumn{2}{c}{0,21} & \multicolumn{2}{c}{0,26} & \multicolumn{2}{c}{ REF } \\
\hline Idade (dias) & Resistência & Desvio & Resistência & Desvio & Resistência & Desvio \\
\hline 1 & 0,49 & 0,07 & 0,33 & 0,10 & 2,85 & 0,29 \\
3 & 1,94 & 0,57 & 1,88 & 0,49 & 3,64 & 0,43 \\
7 & 2,72 & 0,99 & 2,65 & 0,72 & 3,73 & 0,91 \\
11 & 3,31 & 1,09 & 3,68 & 0,74 & 3,05 & 0,51 \\
15 & 4,22 & 1,20 & 3,66 & 1,02 & 3,42 & 0,72 \\
19 & 4,90 & 0,95 & 4,79 & 2,01 & 3,42 & 1,01 \\
23 & 5,10 & 1,11 & 5,13 & 1,56 & 2,96 & 0,35 \\
28 & 5,56 & 0,45 & 5,61 & 0,06 & 2,56 & 0,47 \\
\hline
\end{tabular}




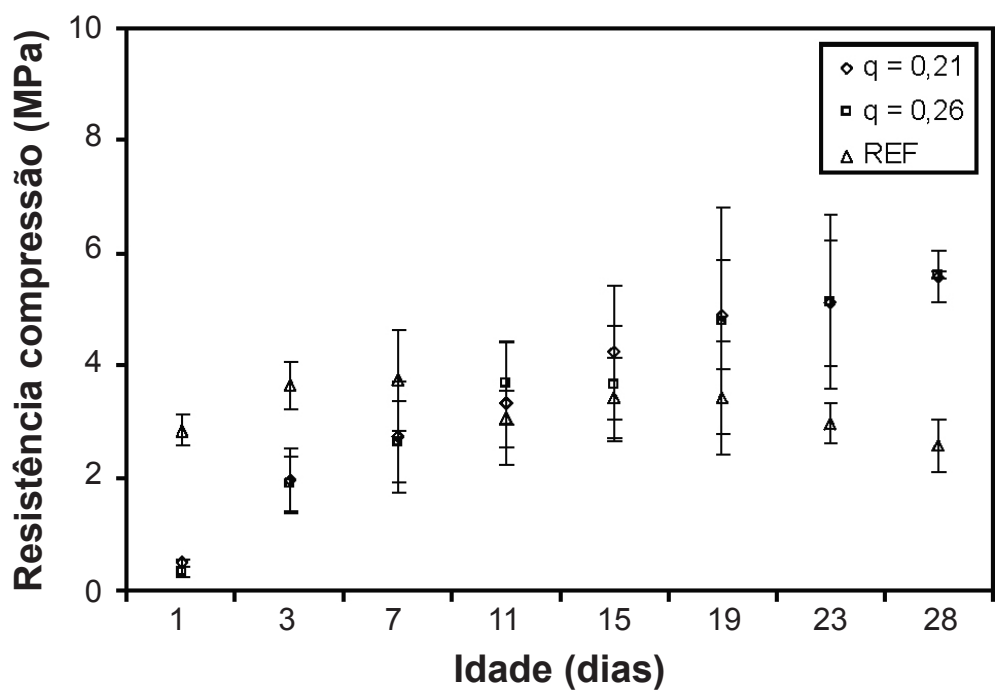

Figura 24: Evolução da resistência à tração por compressão diametral dos concretos ao longo do tempo. [Figure 24: Evolution of the concretes' splitting tensile strength with the time.]

Tabela XIV - Valores da resistência à flexão em 3 pontos (MPa) dos concretos estudados. [Table XIV - Values of 3 point bending strength (MPa) for the studied concretes.]

\begin{tabular}{ccccccc}
\hline Concreto & \multicolumn{2}{c}{0,21} & \multicolumn{2}{c}{0,26} & \multicolumn{2}{c}{ REF } \\
\hline Idade (dias) & Resistência & Desvio & Resistência & Desvio & Resistência & Desvio \\
\hline 1 & 1,71 & 0,08 & 3,48 & 0,30 & 5,37 & 0,28 \\
3 & 5,52 & 0,39 & 6,16 & 0,18 & 6,24 & 0,40 \\
7 & 5,81 & 0,70 & 6,38 & 1,12 & 7,22 & 0,72 \\
11 & 6,75 & 0,55 & 7,33 & 0,10 & 7,10 & 0,69 \\
15 & 8,88 & 0,44 & 9,09 & 0,46 & 8,05 & 0,44 \\
19 & 9,93 & 1,12 & 9,52 & 0,64 & 7,15 & 0,71 \\
23 & 10,15 & 0,53 & 10,05 & 0,77 & 7,36 & 0,44 \\
28 & 10,71 & 0,59 & 11,16 & 0,24 & 7,15 & 0,38 \\
\hline
\end{tabular}

Obs.: Os valores apresentados correspondem à média de 5 determinações.

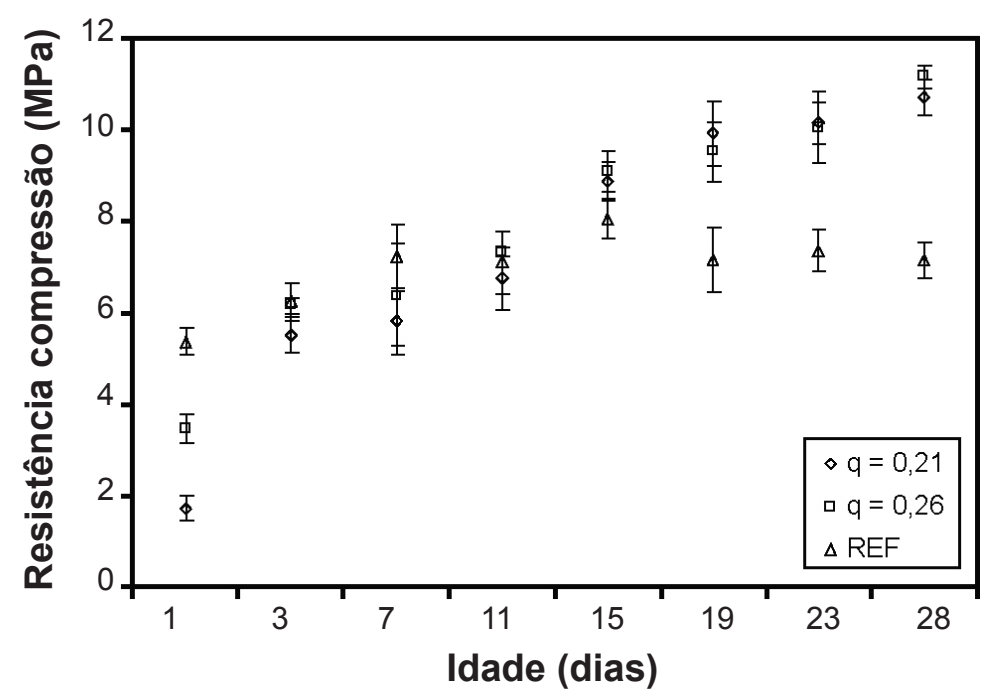

Figura 25: Evolução da resistência à flexão em 3 pontos dos concretos ao longo do tempo. [Figure 25: Evolution of the concretes' 3 point bending strength with time.] 


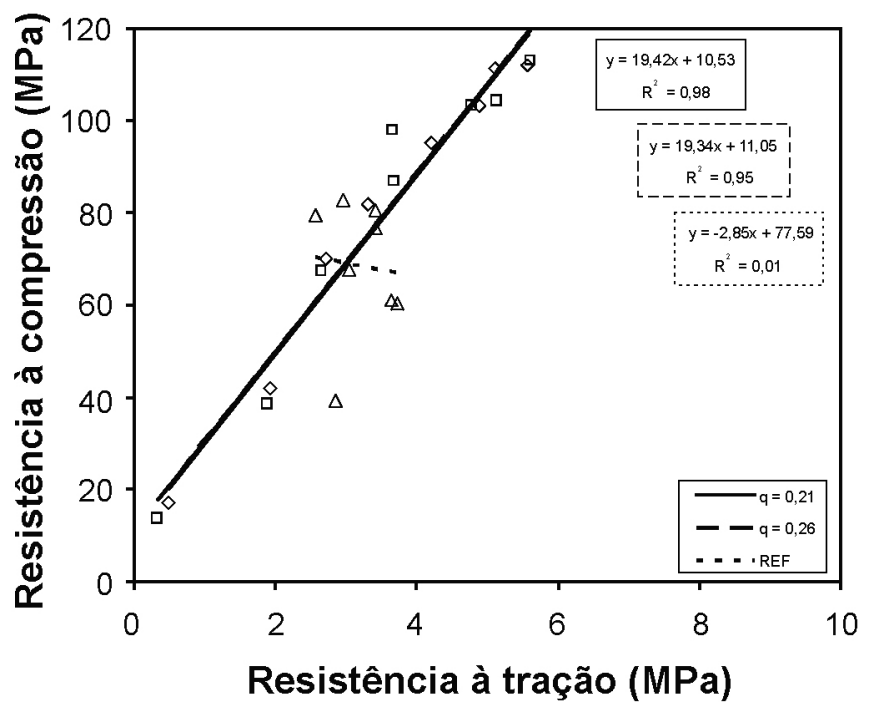

Figura 26: Correlação entre a resistência à compressão e a resistência à tração dos concretos.

[Figure 26: Correlation between compressive strength and tensile strength for the concretes.]

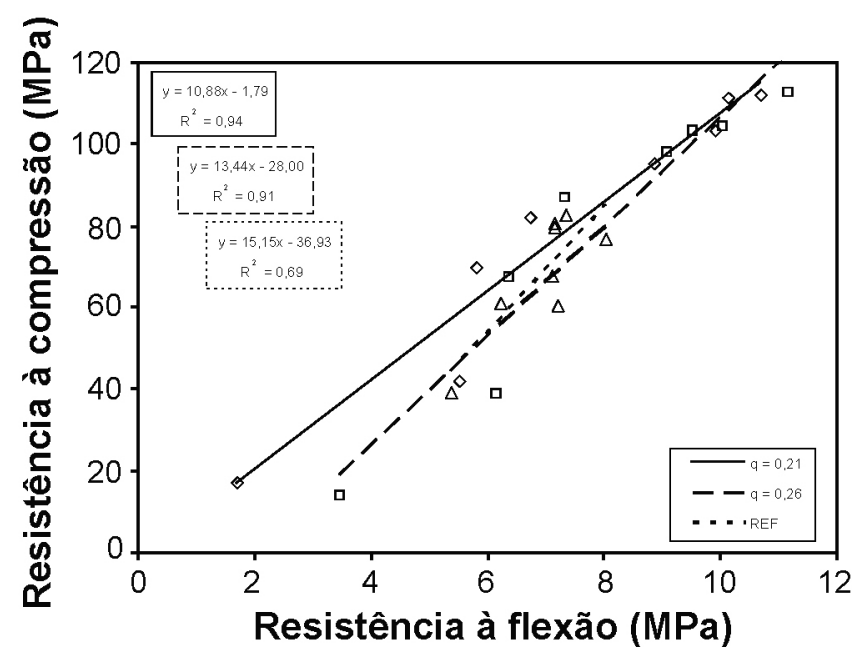

Figura 27: Correlação entre a resistência à compressão e a resistência à flexão dos concretos.

[Figure 27: Correlation between compressive strength and 3 point bending strength for the concretes.]

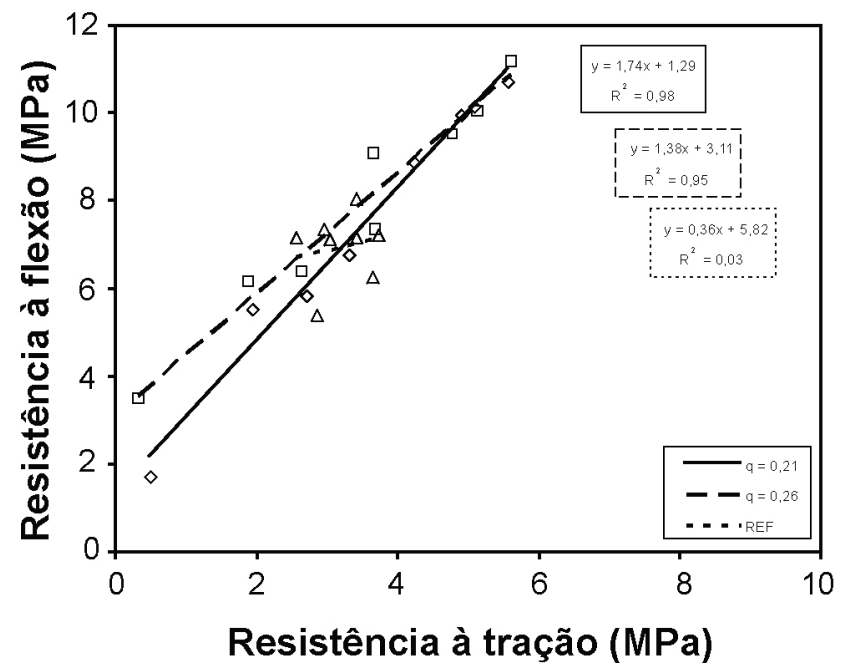

Figura 28: Correlação entre a resistência à flexão e a resistência à tração dos concretos.

[Figure 28: Correlation between 3 point bending strength and tensile strength for the concretes.]

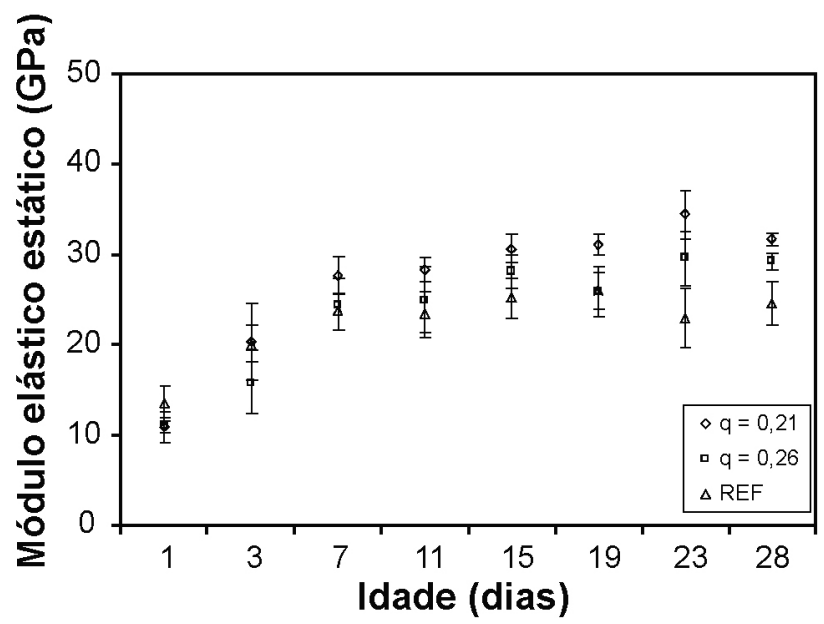

Figura 29: Evolução do módulo de elasticidade estático dos concretos ao longo do tempo.

[Figure 29: Evolution of the concretes' static Young's modulus with the time.]

Tabela XV - Valores do módulo de elasticidade estático (GPa) dos concretos estudados.

[Table XV - Values of static Young's modulus (GPa) for the studied concretes.]

\begin{tabular}{ccccccc}
\hline Concreto & \multicolumn{2}{c}{0,21} & \multicolumn{2}{c}{0,26} & \multicolumn{2}{c}{ REF } \\
\hline Idade (dias) & Módulo & Desvio & Módulo & Desvio & Módulo & Desvio \\
\hline 1 & 10,9 & 1,7 & 11,1 & 0,8 & 13,5 & 2,0 \\
3 & 20,4 & 4,2 & 15,8 & 3,5 & 20,1 & 2,0 \\
7 & 27,7 & 2,1 & 24,5 & 2,8 & 23,7 & 2,1 \\
11 & 28,4 & 1,3 & 25,0 & 3,7 & 23,4 & 2,5 \\
15 & 30,7 & 1,5 & 28,1 & 1,9 & 25,2 & 2,2 \\
19 & 31,1 & 1,2 & 25,9 & 2,7 & 26,0 & 2,0 \\
23 & 34,5 & 2,7 & 29,6 & 3,0 & 23,0 & 3,3 \\
28 & 31,7 & 0,7 & 29,3 & 0,9 & 24,6 & 2,5 \\
\hline
\end{tabular}

Obs.: Os valores apresentados correspondem à média de 5 determinações. 
Tabela XVI - Valores do módulo de elasticidade dinâmico (GPa) dos concretos estudados. [Table XVI - Values of dynamic Young's modulus ( $\mathrm{GPa}$ ) for the studied concretes.]

\begin{tabular}{ccccccc}
\hline Concreto & \multicolumn{2}{c}{0,21} & \multicolumn{2}{c}{0,26} & \multicolumn{2}{c}{ REF } \\
\hline Idade (dias) & Módulo & Desvio & Módulo & Desvio & Módulo & Desvio \\
\hline 1 & 21,3 & 0,5 & 21,6 & ---- & 30,9 & 0,5 \\
3 & 36,2 & 0,5 & 36,8 & 2,9 & 39,3 & 1,0 \\
7 & 43,2 & 0,5 & 43,4 & 3,1 & 40,7 & 1,0 \\
11 & 45,2 & 1,0 & 45,6 & 3,2 & 40,8 & 1,2 \\
15 & 46,6 & 0,8 & 46,9 & 3,6 & 41,6 & 1,0 \\
19 & 47,9 & 1,2 & 47,5 & 2,9 & 43,1 & 0,9 \\
23 & 47,6 & 1,3 & 48,8 & 2,0 & 42,7 & 0,9 \\
28 & 48,5 & 1,1 & 48,7 & 2,5 & 42,7 & 0,6 \\
\hline
\end{tabular}

Obs.: Os valores apresentados correspondem à média de 5 determinações.

tempo, esse efeitoé observado, mesmo o concreto de referência possuindo um melhor empacotamento do sistema granular (maior coeficiente de distribuição). A maior quantidade de finos presente nas novas composições de concreto preenche os poros do sistema granular, enquanto a menor dimensão dos agregados reduz o tamanho crítico do defeito desses materiais. Dessa forma, um melhor desempenho mecânico é observado ao longo do tempo.

As novas composições de concreto permitem obter boas correlações entre as resistências mecânicas medidas, porém, isso não pode ser observado para o desempenho do concreto de referência. Como cada resistência é determinada por um modo de ruptura, a maior heterogeneidade do concreto de referência permite que uma maior quantidade de fatores influencie seu desempenho, dificultando estabelecer uma correlação entre elas.

\section{Módulo de elasticidade}

Há alguns anos, vários pesquisadores procuram estabelecer uma correlação entre os módulos de elasticidade estático

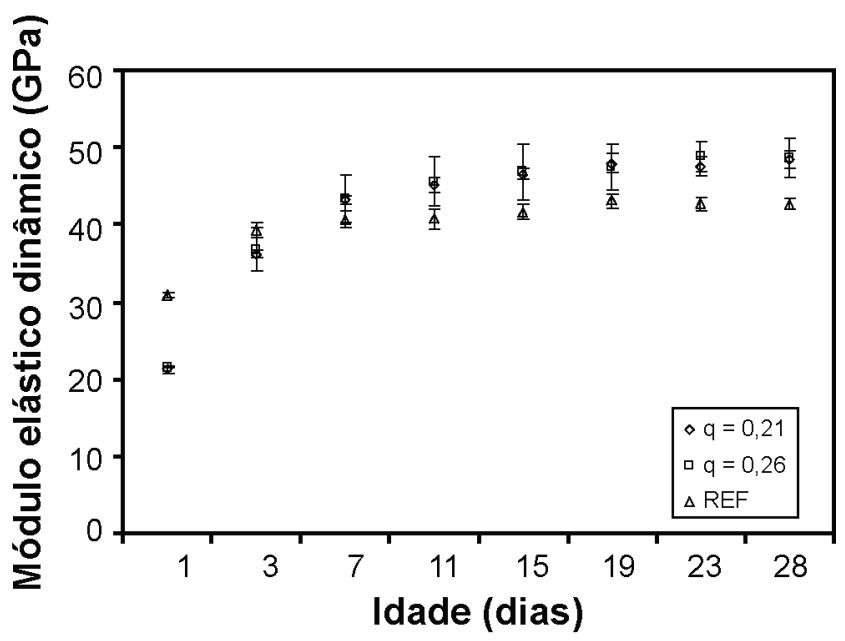

Figura 30: Evolução do módulo de elasticidade dinâmico dos concretos ao longo do tempo.

[Figure 30: Evolution of the concretes' dynamic Young's modulus with the time.]

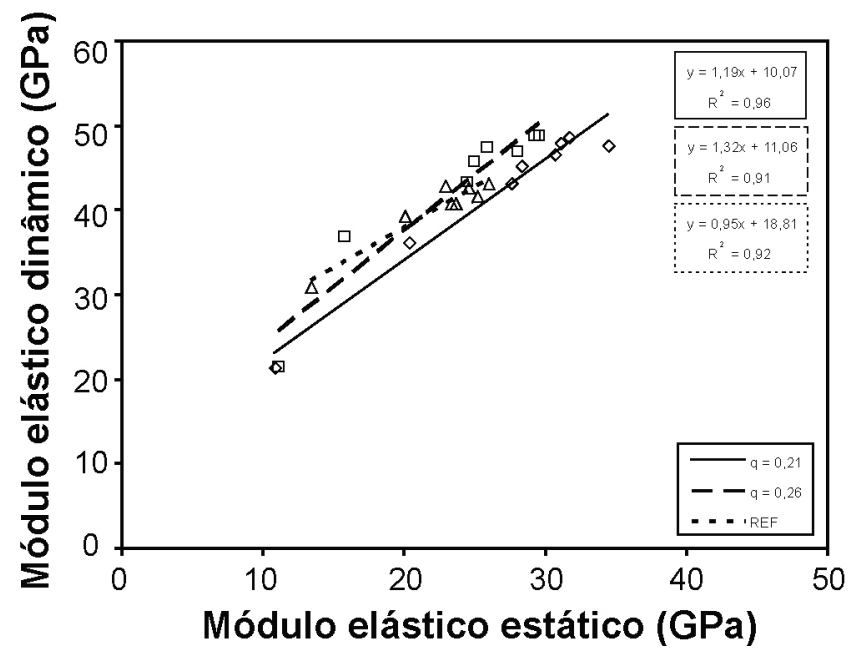

Figura 31: Correlação entre os módulos de elasticidade estático e dinâmico dos concretos.

[Figure 31: Correlation between static and dynamic Young's modulus for the concretes.]

e dinâmico. Esta correlação não é facilmente determinada pela análise do comportamento físico do material, pois a heterogeneidade do concreto influencia os dois módulos de maneiras distintas [24]. Porém, na presente pesquisa, a correlação estabelecida ente os módulos de elasticidade estático e dinâmico foi muito boa para as composições estudadas, sendo o coeficiente de correlação sempre superior a 0,90 . De acordo com a literatura, o módulo de elasticidade dinâmico é indicado como sendo superior que o módulo de elasticidade estático em torno de $20 \%, 30 \%$ e $40 \%$ para concretos de alta, média e baixa resistência, respectivamente [29]. No entanto, no presente estudo, as relações entre os módulos recomendadas na literatura não foram obedecidas, porém o módulo de elasticidade dinâmico medido foi sempre maior que o módulo de elasticidade estático.

\section{CONCLUSÕES}

A aplicação dos conceitos de empacotamento e dispersão de partículas permitiu o desenvolvimento de concretos 
com propriedades superiores até mesmo que outros de alto desempenho amplamente adotado em pesquisas destinadas ao projeto e à aplicação de concretos especiais em obras da construção civil. Além da manutenção da trabalhabilidade por um período mais longo, esses materiais apresentaram um superior desempenho mecânico em idades mais avançadas (28 dias). O melhor desempenho mecânico é obtido pela redução do maior defeito presente no material, ou seja, pela presença de agregados com dimensões inferiores. Além disso, a melhor distribuição do tamanho de partículas das novas composições possibilita uma maior reprodutibilidade dos resultados. Com isso, é possível estabelecer boas correlações entre as propriedades mecânicas desses materiais. Essa boa correlação permite prever a evolução de uma propriedade a partir das outras, sem a necessidade de realizar todos os ensaios de caracterização sempre que um novo lote de concreto for desenvolvido.

Nas próximas etapas do desenvolvimento da pesquisa, o concreto de referência será ajustado pelo método de dosagem computacional para um coeficiente de distribuição igual a 0,26. Com isso, será possível verificar a influência de técnicas mais fundamentais de empacotamento e dispersão de partículas sobre a dosagem de concretos de alto desempenho destinados à construção civil e, assim, estabelecer uma correlação entre os métodos de dosagem experimental (tradicional) e computacional.

\section{AGRADECIMENTOS}

Ao $\mathrm{CNPq}$ - Conselho Nacional de Desenvolvimento Científico e Tecnológico, pela bolsa de estudo e às empresas Holcim Brasil S.A., Elkem Materials South America Ltda., Basf Construction Chemicals Brasil e Mineração Jundu Ltda. pela doação dos materiais utilizados na pesquisa. O apoio do Eng. Fernando Valenzuela na parte experimental também é reconhecido pelos autores.

\section{REFERÊNCIAS}

[1] F. de Larrard, Ultrafine particles for the making of very high strength concretes, Cement Concrete Res. 19, 2 (1989) 161-172.

[2] P.-C. Aïtcin, C. Jolicoeur, J. G. MacGregor, Superplasticizers: how they work and why they occasionally don't, Concrete Int. 16, 5 (1994) 45-52.

[3] I. R. de Oliveira, A. R. Studart, R. G. Pileggi, V. C. Pandolfelli, Dispersão e empacotamento de partículas - princípios e aplicações em processamento cerâmico, Fazendo Arte Editorial, S. Paulo, SP (2000).

[4] D. Bonen, S. L. Sarkar, The superplasticizer adsorption capacity of cement pastes, pore solution composition, and parameters affecting flow loss, Cement Concrete Res. 25, 7 (1995) 1423-1434.

[5] P. Stroeven, M. Stroeven, SPACE system for simulation of aggregated matter application to cement hydration, Cement Concrete Res. 29, 8 (1999) 1299-1304.

[6] M. Sari, E. Prat, J.-F. Labastire, High strength self- compacting concrete: original solutions associating organic and inorganic admixtures, Cement Concrete Res. 29, 6 (1999) 813-818.

[7] C. F. Ferraris, Measurement of rheological properties of high performance concrete: state of the art report, J. Res. NIST 104, 5 (1999) 461-478.

[8] J. E. Wallevik, Relationship between the Bingham parameters and slump, Cement Concrete Res. 36, 7 (2006) 1214-1221.

[9] G. H. Tattersall, P. F. G. Banfill, The rheology of fresh concrete, Pitman, London (1983).

[10] C. Hu, F. de Larrard, The rheology of fresh highperformance concrete, Cement Concrete Res. 26, 2 (1996) 283-294.

[11] P. K. Mehta, P. J. M. Monteiro, Concreto: estrutura, propriedades e materiais, PINI, S. Paulo, SP (1994).

[12] A. M. Neville, Propriedades do concreto, $2^{\text {a }}$ Ed., PINI, S. Paulo, SP (1997).

[13] Associação Brasileira de Normas Técnicas, NBR 7211: agregado para concreto - especificação, Rio de Janeiro, RJ (2005).

[14] Associação Brasileira de Normas Técnicas, NBR NM 248: agregados - determinação da composição granulométrica, Rio de Janeiro, RJ (2003).

[15] A. L. Castro, Aplicação de conceitos reológicos na tecnologia dos concretos de alto desempenho, Tese de Doutorado, IFSC/IQSC/EESC, Universidade de S. Paulo, S. Carlos, SP (2007).

[16] P. R. L. Helene, P. Terzian, Manual de dosagem e controle do concreto, PINI, S. Paulo, SP (1992).

[17] Associação Brasileira de Normas Técnicas, NBR 7810: agregado em estado compactado seco - determinação da massa unitária, Rio de Janeiro, RJ (1983).

[18] American Society for Testing and Materials, ASTM C 830: apparent porosity, liquid absorption, apparent specific gravity, and bulk density of refractory shapes by vacuum pressure (1993).

[19] Associação Brasileira de Normas Técnicas, NBR 5739: concreto - ensaio de compressão de corpos-de-prova cilíndricos, Rio de Janeiro (1994).

[20] American Society for Testing and Materials, ASTM C 496: splitting tensile strength of cylindrical concrete specimens (1990).

[21] American Society for Testing and Materials, ASTM C 133: cold crushing strength and modulus of rupture of refractories (1994).

[22] Associação Brasileira de Normas Técnicas, NBR 8522: concreto - determinação dos módulos estáticos de elasticidade e de deformação e da curva tensão-deformação, Rio de Janeiro (2003).

[23] American Society for Testing and Materials. ASTM C 1259: Dynamic Young's modulus, shear modulus, and Poisson's ratio for advanced ceramics by impulse excitation of vibration (1994).

[24] S. F. Almeida, Análise dinâmica experimental da rigidez de elementos de concreto submetidos à danificação progressiva até a ruptura, Dissertação de Mestrado, Escola 
de Engenharia de S. Carlos, Universidade de S. Paulo, S. Carlos, SP (2005).

[25] R. D. Vanderlei, Análise experimental do concreto de pós reativos: dosagem e propriedades mecânicas, Tese de Doutorado, Escola de Engenharia de S. Carlos, Universidade de S. Paulo, S. Carlos, SP (2004).

[26] S. Suhr, Proc. Int. Conf. "Rheology of Fresh Cement and Concrete", Eds.: P. F. G. Banfill, E \& FN Spon, Liverpool, UK (1990) 37-46.

[27] M. Nehdi, S. Mindess, P.-C. Aitcin, Rheology of highperformance concrete: effect of ultrafine particles, Cement
Concrete Res. 28, 5 (1998) 687-697.

[28] W. Aiqin, Z. Chengzhi, Z. Ningsheng, The theoretical analysis of the influence of the particle size distribution of cement system on the property of cement, Cement Concrete Res. 29, 11 (1999) 1721-1726.

[29] P. G. B. Nóbrega, Análise dinâmica de estruturas de concreto: estudo experimental e numérico das condições de contorno de estruturas pré-moldadas, Tese de Doutorado, Escola de Engenharia de S. Carlos, Universidade de S. Paulo, S. Carlos, SP (2004).

(Rec. 26/02/2008, Ac. 19/06/2008) 